\title{
Currency Areas and Monetary Coordination*
}

\author{
Qing Liu \\ University of Toronto \\ (qing.liu@utoronto.ca)
}

\author{
Shouyong Shi \\ University of Toronto \\ (shouyong@chass.utoronto.ca)
}

April 2006

\begin{abstract}
In this paper we integrate the recent development in monetary theory with international finance, in order to examine the coordination between two currency areas in setting long-run inflation. The model determines the value of each currency and the size of each currency area without requiring buyers to use a particular currency to buy a country's goods. We show that the two countries inflate above the Friedman rule in a non-cooperative game. Coordination between the two areas reduces inflation to the Friedman rule, increases consumption, and improves welfare of both countries. This gain from coordination increases as the two areas become more integrated in trade. These results arise from the new features of the model, such as the deviations from the law of one price and the extensive margin of trade. To illustrate these new features, we show that introducing a direct tax on foreign holdings of a currency does not eliminate a country's incentive to inflate, while it does in traditional models.
\end{abstract}

JEL Classifications: F41, E40.

Keywords: Exchange rates, currency areas, coordination.

* Address: Department of Economics, University of Toronto, 150 St. George Street, Toronto, Ontario, Canada, M5S 3G7. We have received useful comments from the participants of the workshops at the Federal Reserve Bank of Cleveland, Federal Reserve Bank of Minneapolis and Bank of Canada. The second author would like to gratefully acknowledge the financial support from the Social Sciences and Humanities Research Council of Canada and from the Bank of Canada Fellowship. The opinion expressed here is the authors' own and it does not represent the view of the Bank of Canada. 


\section{Introduction}

Currency areas play an important role in international trade. The formation of the Euro area, for example, increases the efficiency of trade by reducing the number of currencies used. However, it also increases the vulnerability of trade to monetary policy. Inflation affects more countries when a currency area is larger. Also, the monetary authority in a large currency area may have greater temptation to use inflation to redistribute the purchasing power from other currency areas to itself. This temptation raises the following questions about the coordination between currency areas: (i) Does the coordination between two currency areas in setting long-run inflation enhance welfare in each area relative to policy competition? (ii) Does the need for monetary coordination increase when two currency areas become more integrated in trade?

These questions have been addressed in New Open Economy Macroeconomics (e.g., Obstfeld and Rogoff, 2002). However, this literature imposes ad hoc assumptions to give each currency a unique role that cannot be replaced with other currencies. Examples include cash-in-advance constraints and money in the utility function. We eliminate these assumptions by integrating the recent development in monetary theory with international finance. The resulting model not only provides a new foundation for international finance, it also generate new results on monetary coordination that cannot be obtained in traditional models.

To motivate the analysis, let us illustrate how sensitively the results in the literature depend on ad hoc assumptions regarding currencies. Consider the assumption of a cash-in-advance constraint that requires purchases to be made with the seller country's currency. Suppose that there are two countries whose goods are perfectly substitutable and are produced using elastically supplied labor. ${ }^{1}$ Then, a unilateral increase in inflation in one country reduces the purchasing power of the corresponding currency and consumption of the country's residents. There is no incentive for a country to inflate and, hence, no need for the countries to coordinate on long-run inflation.

The result is reversed if all currencies can be used to purchase all goods. In this case, the two currencies differ only in their growth rates and there are a continuum of equilibria that differ in the nominal exchange rate. In each equilibrium, the nominal exchange rate is constant over time. A version of the so-called Gresham's Law emerges. That is, the currency whose supply grows at a higher rate than the other currency will represent an increasing fraction of agents'

\footnotetext{
${ }^{1}$ This description of the economy extends the one in Helpman (1981) from an endowment economy to a production economy.
} 
currency portfolios over time. This feature provides a strong incentive for each country to inflate. ${ }^{2}$ Coordination reduces inflation and increases welfare for both countries.

A similar sensitivity exists in models that put money into utility functions. In common, ad hoc assumptions on the role of a currency make this role irresponsive to monetary policy. In these models, the well-known Lucas critique applies to the welfare analysis of monetary policy, especially when the policy concerns currency competition and monetary coordination.

To eliminate these problems, we derive a role for a currency using search theory of money (see Shi, 1995, and Trejos and Wright, 1995). As in the above exposition, the two countries have the same production technology and preferences. The countries produce identical sets of goods and all goods are tradeable between the two countries. There are two goods markets and one currency market. All markets are separated, and so there cannot be instantaneous arbitrage between two markets. The currency market is centralized and Walrasian. The goods markets are decentralized in the sense that the exchange is modelled as random matching. A currency derives a positive value in the equilibrium by alleviating the difficulty of exchange, but it does not yield direct utility or facilitate production.

We assume that each goods market uses a particular currency. For the convenience of grouping transactions by the currency used, we refer to each goods market as a currency area. ${ }^{3}$ The size of a currency area is determined by households' choice of how often to buy from each area. Because the goods sold in the two areas are perfect substitutes, this choice implies that a household is not subject to cash-in-advance constraints for purchases. Moreover, sellers from both countries are present in each area, and so a country's goods are sold for both currencies.

There are three exogenous asymmetries between the two countries. First, the matching process exhibits local congestion. That is, by entering a goods market, a buyer increases congestion by more for other buyers from the same country than for the other country's buyers. Second, monetary transfers are asymmetric, as they are given only to domestic households. Third, the two goods markets may not be fully integrated in the sense that transaction costs make more sellers sell in their domestic currency area than in the foreign currency area.

\footnotetext{
${ }^{2}$ The same result emerges in the overlapping-generations model of Kareken and Wallace (1981). The incentive to inflate also exists in the hybrid model by King et al. (1992), who impose a cash-in-advance constraint on a fraction, but not all, of the population with overlapping generations.

${ }^{3}$ In the common usage, the term "currency area" refers to a group of countries that issue the same currency. According to this usage, each country in our model is a currency area. However, our usage of the term helps us to distinguish the use from the issuing of a currency. As in reality, importers and exporters of the countries that issue the same currency do not use that currency in all trades.
} 
We establish the following results. First, both currencies are valued in the equilibrium, where the nominal exchange rate and the size of each currency area depend on fundamental factors such as money growth rates. Second, when the two countries play a non-cooperative policy game, inflation rates in the Nash equilibrium exceed the Friedman rule. Coordination reduces inflation to the Friedman rule and leads to a Pareto improvement for the two countries. Third, when the two goods markets become more integrated, the temptation for each country to inflate is higher, and so the welfare gain from coordination is larger.

These results may sound familiar but their causes are fundamentally different from traditional models. Key to the need of coordination are the deviations from the law of one price and the effect of inflation on the number of trades, both of which are absent in traditional models. We illustrate these new causes in two ways. First, we push our model to the limit which resembles the cash-in-advance economy examined by Helpman (1981). In contrast to Helpman's model, a gain from coordination exists even in this limit of our model. Second, we introduce a tax on foreign holdings of a currency. In traditional models, allowing each country to set this tax optimally will eliminate a country's incentive to inflate and, hence, eliminate the need of monetary coordination. In our model, a country continues to have incentive to inflate after it sets the direct tax optimally. Inflation achieves redistribution in more ways than the direct tax does.

Our model extends search theory of money to a two-country environment with divisible money and money growth. ${ }^{4}$ In this literature, the paper closest to ours is the one by Head and Shi (2003). The main difference is that Head and Shi do not model currency areas or examine monetary coordination. Another difference is that Head and Shi model the currency exchange as random bilateral matches. We model the currency market as a centralized market, which seems more realistic (see Obstfeld, 1998, for a discussion).

On monetary coordination, there is a large literature in New Open Economy Macroeconomics. As we said earlier, this literature imposes ad hoc assumptions on the role of a currency. In addition, the literature does not focus on long-run inflation; instead, it focuses on whether countries should use short-run inflation to offset other types of shocks. An exception is Cooley and Quadrini

\footnotetext{
${ }^{4}$ One of the first papers in search theory of money is Kiyotaki and Wright (1993). Early applications of the theory to multiple currencies and exchange rates include Matsuyama, et al. (1993), Shi (1995), Zhou (1997) and Wright and Trejos (2001). These applications have assumed money or goods, or both, to be indivisible. As a result, they are not suitable for analyzing money growth and inflation. Camera et al. (2004) allow agents to hold two units of money. The current model eliminates the restriction of indivisibility by using the device in Shi (1997). Craig and Waller (2004) also construct a model with two currencies, but their model admits only numerical solutions.
} 
(2003), with which we will compare our model in section 7. Finally, there is a literature that examines whether monetary coordination is beneficial when optimal monetary policy is time inconsistent (e.g., Rogoff, 1985). We abstract from this issue of credibility.

\section{The Model}

\subsection{The Environment}

Consider a world consisting of two countries, labelled 1 and 2. In each country, there are many types of infinitely-lived households. The households of each type can produce only a particular type of goods, at a cost (disutility) $\phi(q)=q^{\sigma}$ for $q$ units of production, where $\sigma>1$. They consume only another type of goods. Without loss of generality, we let the utility function of consumption be $u(q)=A q$, where $A>0$ is a constant. To focus on monetary trades, we exclude barter by assuming that there is no double coincidence of wants between the households. All goods are nonstorable.

A household consists of a continuum of members. The members do not make decisions; instead, they trade according to the instructions given by the household and regard the household's utility as the common objective. The total measure of the members in the household is 2 , with a unit measure of buyers and a unit measure of sellers. Sellers produce and sell goods, while buyers use money to buy consumption goods for all members to share. This construct of large households simplifies the analysis by smoothing the matching risks within a households and, hence, making the distribution of money holdings across households degenerate. ${ }^{5}$

The two countries have the same size, preferences and production technology. All goods are tradeable between the two countries and there is no distinction between the same type of goods produced in the two countries. Each country issues one currency. One distinction between the two countries is that the monetary authority of a country makes monetary transfers only to domestic households. A currency does not generate direct utility or facilitate production. Moreover, a household can use both currencies to purchase a country's goods. This description of the world abstracts from a large part of the gains from international trade in reality, but it presents the simplest setup for an analysis of the nominal exchange rate and monetary coordination. If monetary coordination is desirable in this environment, one could see an even larger benefit from

\footnotetext{
${ }^{5}$ This modelling device is a proxy for a single agent's time allocation during a period. See Shi (1997) for a discussion.
} 
coordination in a real world where the gains from trade are larger.

There are two markets for goods and one market for currencies. These markets are separated from each other. The currency market is centralized and Walrasian, but the goods markets are decentralized and modelled as random matching. Each goods market uses a specific currency; the one using currency $i$ is referred to as country $i$ 's domestic currency area. The assumption of currency areas precludes the possibility that two currencies are accepted in one market. Why the exchange of goods is organized this way is an interesting question, but it is not the question to be answered here. We take the existence of currency areas as given and focus on the question whether monetary coordination between the currency areas is desirable. ${ }^{6}$ The size of a currency area is determined endogenously by households' allocation of buyers to the area. Let $n_{i}$ be the fraction of buyers of a household in country $i$ who go to the domestic currency area.

In contrast to this endogenous allocation of buyers, we fix the fraction of sellers who go to the domestic area at a number $s \in[1 / 2,1]$. What we have in mind is an environment in which it is costly to send sellers to the foreign currency area, relative to the domestic currency area. This cost limits the fraction of a country's sellers who go to the foreign currency area to $(1-s)$. The number $(1-s)$ captures the degree of the integration between the two markets. In the case $s=1 / 2$, the two countries' sellers have equal access to the two markets. We refer to this case as a fully integrated world economy and take it as the benchmark.

Let us clarify a few aspects of the modelling above. First, the assumption of currency areas does not imply cash-in-advance constraints. On the buyers' side, a household can avoid using a particular currency by not sending any buyer to the area which uses that currency. The household can obtain identical goods by buying in the other area, instead. On the sellers' side, a household sells goods for both currencies, provided $s<1$. Only in the special case $s=1$ are goods sold entirely for the seller's domestic currency. Second, the assumptions of currency areas and a fixed $s$ are not sufficient to determine the nominal exchange rate uniquely, as we will demonstrate later. This insufficiency is another support for the claim that the modelling above does not feature cashin-advance constraints, because such constraints lead to a uniquely determined nominal exchange rate (e.g., Helpman, 1981). Third, a reason for fixing $s$ is tractability. The fixed $s$ allows us to

\footnotetext{
${ }^{6}$ The following environment can generate the currency areas endogenously. Imagine that goods must be sold through vending machines and that each machine is programmed to take in only one type of currency (perhaps because there is an additional cost to allow a machine to take in two types of currencies). Without currency areas, mismatches can occur as a machine may not take in the particular currency carried by a buyer. Separating the machines into two areas eliminates the mismatches.
} 
simplify the analysis significantly by assuming later that the buyer in a trade makes a take-it-orleave-it offer. If one maintains this assumption on bargaining and allows households to choose $s$, then any choice of $s$ will be consistent with an equilibrium because sellers get zero surplus no matter where they trade. ${ }^{7}$ If one changes the assumption on bargaining to give a seller a positive share of the match surplus, then endogenizing $s$ will make the analysis intractable.

We illustrate the currency areas and the currency market in Figure 1.

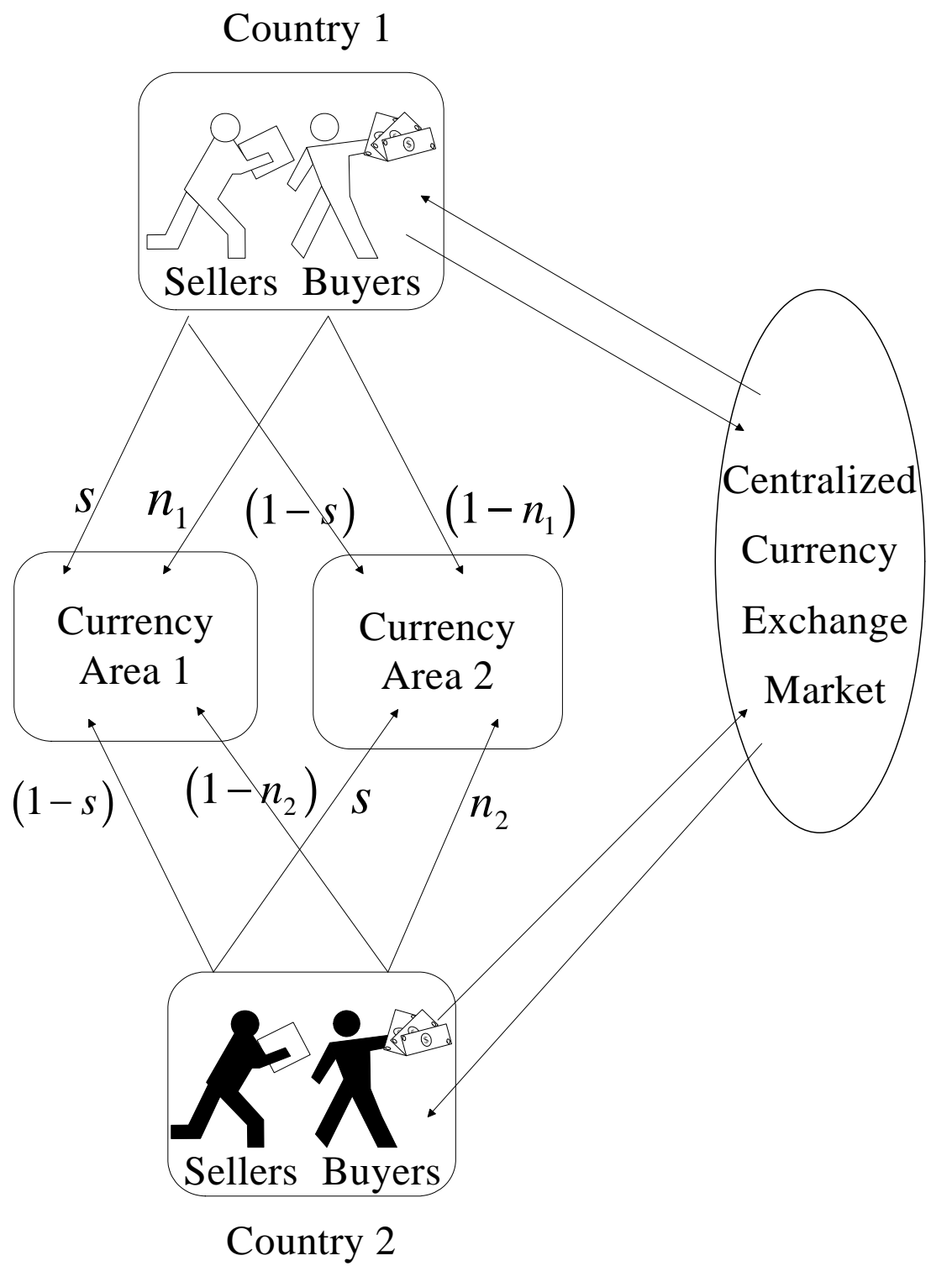

Figure 1. Illustration of the environment

\footnotetext{
${ }^{7}$ This indeterminacy of $s$ leads to indeterminacy of the nominal exchange rate. However, for each value of $s$, the nominal exchange rate responds to money growth. Thus, the indeterminacy is different from that in Kareken and Wallace (1981), where the nominal exchange rate is endogenously fixed.
} 


\subsection{Matches and Trading Quantities}

Agents are matched randomly and bilaterally in each area. As described earlier, no match has a double coincidence of wants. Matches can have a single coincidence of wants, where the seller can produce the consumption goods for the buyer. We call such a match a trade match. In each area $k$, there are four types of trade matches as depicted in Figure 2.

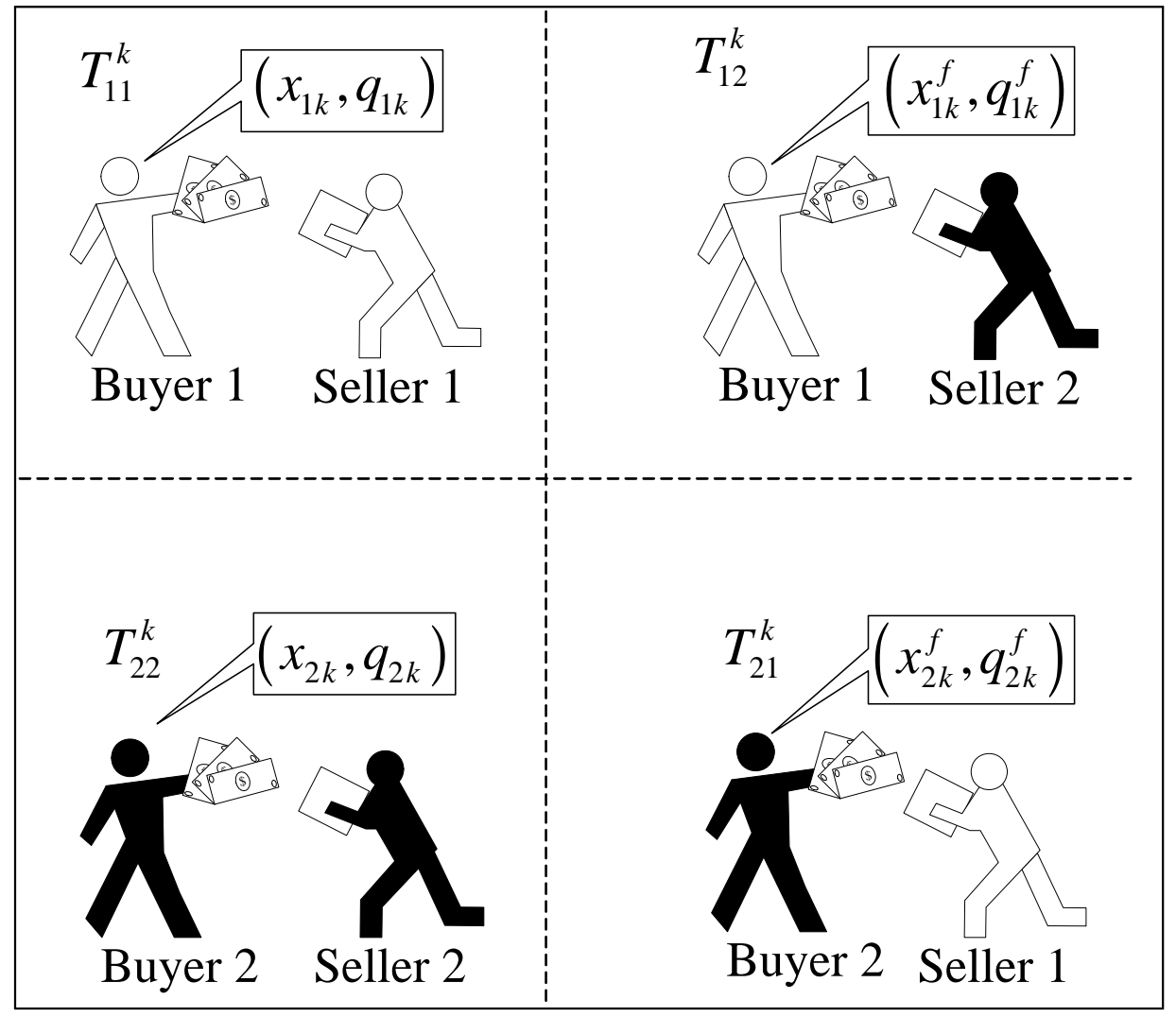

Figure 2. Trade matches in currency area $k$

The notation $T_{i j}^{k}$ stands for the total number of trade matches in area $k$ between country $i$ buyers and country $j$ sellers. Let $S_{j k}$ be the number of country $j$ sellers in area $k$, where $S_{j k}=s$ if $j=k$ and $S_{j k}=1-s$ if $j \neq k$. Let $N_{i k}$ be the number of country $i$ buyers in area $k$, where $N_{i k}=N_{i}$ if $i=k$ and $N_{i k}=1-N_{i}$ if $i \neq k$. We assume that $T_{i j}^{k}$ is given by the following matching function:

$$
T_{i j}^{k}=L\left(N_{i k}\right) S_{j k}
$$

where $L(N)=\min \left\{L_{0}(N)^{\psi}, N\right\}, \psi \in(0,1)$, and $0<L_{0}<1$. Since $S$ is fixed, the matching function is equivalent to a Cobb-Douglas function up to rescaling $L_{0}$. 
Denote $\mu(N)=L(N) / N$. A buyer from country $i$ has a trade match with a seller from country $j$ in area $k$ with probability $T_{i j}^{k} / N_{i k}=\mu\left(N_{i k}\right) S_{j k}$. Similarly, a seller from country $j$ has a trade match with a buyer from country $i$ in area $k$ with probability $T_{i j}^{k} / S_{j k}$. Because the function $L$ is bounded below $N, \mu(N) \leq 1$ and so the trading probabilities are indeed bounded below one.

The matching function introduces an important asymmetry between the two countries - "local congestion" in the market. That is, if a buyer enters an area, he crowds out other buyers from the same country by more than crowding out the other country's buyers. In fact, we push this asymmetry to the extreme version in which a buyer does not crowd out the other country's buyers. For example, a country 1 buyer meets a country $j$ seller in area $k$ with probability $\mu\left(N_{1 k}\right) S_{j k}$, which decreases with the number $N_{1 k}$ but is independent of $N_{2 k}$. Asymmetric matching is necessary for our results, but the extreme asymmetry is not.

Asymmetric matching seems a reasonable distinction between countries. To see this, consider the following environment. There are two trading posts in each market, indexed by $i=1,2$. Buyers of country $i$ go to post $i$ with probability $p$ and to post $i^{\prime}$ with probability $(1-p)$, where $i^{\prime} \neq i$. Sellers who come to the area go to each post with probability $1 / 2$. At each post, agents are randomly matched and the number of matches is $L(N) S$, where $N$ and $S$ are the numbers of buyers and sellers at the post. If $p=1$, this matching process delivers the matching function assumed above. In general, local congestion exists if $p>1 / 2$. The assumption $p>1 / 2$ captures the realistic feature that foreigners typically buy from particular exporters or they are concentrated in the regions near the national border.

With the matching function, (2.1), local congestion exists when $\psi<1$. Coincidently, the assumption $\psi<1$ also implies that the matching function is concave in the number of buyers. However, for the determination of the nominal exchange rate, concavity is not as important as the asymmetry implied by local congestion. For example, if we change the specification of the total number of trade matches with country $j$ sellers in area $k$ to $L\left(N_{1 k}+N_{2 k}\right) S_{j k}$, then the matching function is concave when $\psi<1$, but it is symmetric between the two countries. In this case, the nominal exchange rate would be indeterminate. With this clarification in mind, we will refer to the feature $\psi<1$ as local congestion. ${ }^{8}$

We have described all exogenous differences between the two countries. The first is local

\footnotetext{
${ }^{8}$ Concavity plays a role in ruling out the corner solutions $n_{1}=1$ and $n_{1}=0$ as an equilibrium. If no other buyer goes to an area, then it is optimal for an individual buyer to go to that area because such a buyer will be guaranteed a trade match provided that there are some sellers in that area.
} 
congestion in the matching process. The second is asymmetric monetary transfers; that is, only domestic households receive the transfers of the domestic currency. The third is the lack of integration between the two markets, which is present when $s \neq 1 / 2$.

Now, let us turn to the notation $(x, q)$ in Figure 2. These are the quantities of money and goods exchanged in a trade. We assume that the buyer in a match makes a take-it-or-leave-it offer. The buyer offers $x$ units of money for $q$ units of goods. The first subscript of $x$ and $q$ indicates the buyer's country, the second subscript indicates the currency used in the trade, and the superscript $f$ indicates that the trade is between agents from different countries. For example, in a match with a county 2 seller in area 1 , a buyer from country 1 proposes $\left(x_{11}^{f}, q_{11}^{f}\right)$, and a buyer from country 2 proposes $\left(x_{21}, q_{21}\right)$.

To simplify the notation, we normalize all nominal prices and quantities involving currency $k$ by the total stock of currency $k, M_{k}$. For example, the actual amount of money $k$ that a buyer of country $i$ offers to a seller of country $i$ is $x_{i k} M_{k}$. Similarly, we normalize the nominal exchange rate by the ratio of the stocks of the two currencies. Denote this normalized exchange rate as $e$. The actual exchange rate is $e M_{2} / M_{1}$, which is the number of units of currency 2 that are needed to exchange for one unit of currency 1.

\subsection{Timing of Events}

The events in an arbitrary period $t$ unfold as in Figure 3, where the subscript $t$ is suppressed. At the beginning of period $t$, each household in country $i$ receives lump-sum monetary transfers of currency $i$. The quantity of this transfer is $r_{i, t-1} M_{i, t-1}$, where

$$
r_{i, t-1}=\gamma_{i, t-1}-1, \quad i=1,2
$$

Thus, the stock of currency $k$ grows at the (gross) rate $\gamma_{k, t}$ between periods $t$ and $t+1$. After the transfer, the household's money holdings are measured. Denote the (normalized) holdings of currency $k$ by a country $i$ household as $m_{i k}$.

Markets open sequentially. The currency market opens first. ${ }^{9}$ A country $i$ 's household sends a (normalized) amount of currency $k, f_{i k}$, to the currency market. After the exchange, the currency market closes. Then, a country $i$ household chooses $n_{i}$, the fraction of buyers going to currency

\footnotetext{
${ }^{9}$ Because there is no uncertainty in our model, whether the currency market opens before, after, or at the same time as the goods markets is not important for the analytical results. The important assumption is that these markets are separated so that there is no instantaneous arbitrage between them. However, the timing assumed here simplifies the algebra.
} 
area $i$. All buyers who go to the same area are given the same amount of currency. Then, the goods market in each area opens, matches are generated, and agents trade the quantities $(x, q)$. During the exchange, matches are separated from each other. After the exchange, agents bring back the goods and money. A household allocates the same amount of consumption to all members. Then, time proceeds to the next period.

\begin{tabular}{|c|c|c|c|c|c|}
\hline & $\begin{array}{l}\text { Money holding } \\
\text { are measured }\end{array}$ & $\begin{array}{l}\text { Currency } \\
\text { market opens }\end{array}$ & $\begin{array}{l}\text { Household's } \\
\text { decision }\end{array}$ & $\begin{array}{l}\text { Goods markets } \\
\text { open }\end{array}$ & Markets close \\
\hline $\begin{array}{l}\text { Receiving } \\
r_{i} M_{i}\end{array}$ & $\left(m_{i 1}, m_{i 2}\right)$ & exchange $f_{i k}$ & $\begin{array}{c}n_{i},\left(x_{i k}, q_{i k}\right) \\
\left(x_{i k}^{f}, q_{i k}^{f}\right)\end{array}$ & $\begin{array}{l}\text { Matches and } \\
\text { exchanges }\end{array}$ & $\begin{array}{l}\text { Household } \\
\text { allocates } \\
\text { consumption goods }\end{array}$ \\
\hline
\end{tabular}

Figure 3. Timing of events in period $t$

\subsection{The Representative Household's Decision Problem}

We pick an arbitrary household in country $i$ as the representative household of country $i$. Shorten the time subscript $t \pm i$ to $\pm i$, where $i>0$. The representative household makes the following decisions: (i) the allocation of buyers to each currency area, $\left(n_{i}, 1-n_{i}\right)$; (ii) the terms of trade, $\left(x_{i k}, q_{i k}\right)$ and $\left(x_{i k}^{f}, q_{i k}^{f}\right)$, which a buyer will propose in a trade match in area $k$; (iii) future money holdings of each currency, $m_{i k,+1}$; (iv) the amount of currency $k, f_{i k}$, to be exchanged in the currency market. As said earlier, the nominal quantities $\left(x_{i k}, x_{i k}^{f}, f_{i k}, m_{i k}\right)$ are ones normalized by $M_{k}$. Denote the household's decisions as

$$
h_{i}=\left[n_{i}, m_{i 1,+1}, m_{i 2,+1}, f_{i 1},\left(x_{i k}, q_{i k}, x_{i k}^{f}, q_{i k}^{f}\right)_{k=1,2}\right] .
$$

Use the corresponding upper-case letters to denote other households' decisions or aggregate variables, which the representative household takes as given.

Let $v\left(m_{i 1}, m_{i 2}\right)$ be the value function of the representative household in country $i$. Define

$$
\omega_{i k}=\frac{\beta}{\gamma_{k}} v_{k}\left(m_{i 1,+1}, m_{i 2,+1}\right), i=1,2 ; k=1,2 .
$$

Here $v_{k}$ denotes the partial derivative of the value function with respect to the $k$ th argument. The variable $\omega_{i k}$ is country $i$ representative household's marginal value of next period's holdings 
of currency $k$, discounted to the current period. The discounting includes the money growth rate, as well as timing discounting, because $m$ is normalized by the aggregate stock which grows over time. To shorten the terminology, we call $\omega_{i k}$ country $i$ representative household's valuation of currency $k$. Similarly, the valuation of currency $k$ of other households in country $i$ is $\Omega_{i k}$.

We formulate the maximization problem of the representative household of country 1 . A similar formulation applies to country 2 household's problem. To do so, compute the household's consumption in a period as:

$$
c=n_{1}\left(\frac{T_{11}^{1}}{N_{1}} q_{11}+\frac{T_{12}^{1}}{N_{1}} q_{11}^{f}\right)+\left(1-n_{1}\right)\left(\frac{T_{11}^{2}}{1-N_{1}} q_{12}+\frac{T_{12}^{2}}{1-N_{1}} q_{12}^{f}\right)
$$

The terms in the first bracket are the expected amount of goods obtained by one of the household's buyers from currency area 1 and the terms in the second bracket are the expected amount of goods from area 2. There are two terms inside each bracket because a buyer has positive probability of trading with a seller from either country.

Similarly, the household's disutility of production in a period is:

$$
\mathcal{P}=\left[T_{11}^{1}\left(Q_{11}\right)^{\sigma}+T_{21}^{1}\left(Q_{21}^{f}\right)^{\sigma}\right]+\left[T_{11}^{2}\left(Q_{12}\right)^{\sigma}+T_{21}^{2}\left(Q_{22}^{f}\right)^{\sigma}\right]
$$

Notice the difference between the lower-case and upper-case letters in (2.2) and (2.3).

The representative household chooses $h_{1}$ to solve the following maximization problem:

$$
(P H) \quad v\left(m_{11}, m_{12}\right)=\max \left\{u(c)-\mathcal{P}+\beta v\left(m_{11,+1}, m_{12,+1}\right)\right\}
$$

subject to following constraints:

$$
\begin{aligned}
& \Omega_{1 k} x_{1 k}-\left(q_{1 k}\right)^{\sigma}=0 ; k=1,2 ; \\
& \Omega_{2 k} x_{1 k}^{f}-\left(q_{1 k}^{f}\right)^{\sigma}=0 ; k=1,2 ; \\
& \frac{m_{11}-f_{11}}{n_{1}} \geq x_{11} ; \quad \frac{m_{11}-f_{11}}{n_{1}} \geq x_{11}^{f} ; \\
& \frac{m_{12}+e f_{11}}{1-n_{1}} \geq x_{12} ; \quad \frac{m_{12}+e f_{11}}{1-n_{1}} \geq x_{12}^{f} .
\end{aligned}
$$

In addition, the following laws of motion of money holdings must hold:

$$
\begin{aligned}
\gamma_{1} m_{11,+1}= & \left(m_{11}-f_{11}\right)-n_{1}\left(\frac{T_{11}^{1}}{N_{1}} x_{11}+\frac{T_{12}^{1}}{N_{1}} x_{11}^{f}\right) \\
& +\left(T_{11}^{1} X_{11}+T_{21}^{1} X_{21}^{f}\right)+\left(\gamma_{1}-1\right)
\end{aligned}
$$




$$
\begin{aligned}
\gamma_{2} m_{12,+1}= & \left(m_{12}+e f_{11}\right)+\left(T_{11}^{2} X_{12}+T_{21}^{2} X_{22}^{f}\right) \\
& -\left(1-n_{1}\right)\left(\frac{T_{11}^{2}}{1-N_{1}} x_{12}+\frac{T_{12}^{2}}{1-N_{1}} x_{12}^{f}\right) .
\end{aligned}
$$

The constraints (2.4) and (2.5) are the sellers' participation constraints in a trade in area $k$. The left-hand side of each of these constraints is the seller's surplus from trade. To induce the seller to trade, the buyer's offer should give the seller a non-negative surplus. Since the buyer makes a take-it-or-leave-it offer, the seller's surplus is zero, and the participation constraints are binding in equilibrium.

Buyers in trade matches also face the constraints (2.6) and (2.7). These constraints require that each buyer should not spend more money than he carries into the trade. These restrictions arise from the trading environment that the matches are separated from each other, which prevents the buyers from using the left-over money balance of other buyers in the household. Note that the amount of money each buyers carries into the goods markets includes the amount the household received from the currency trade.

Finally, (2.8) and (2.9) are the laws of motion of the household's holdings of the two currencies. In (2.8), the left hand side of this constraint is the household's holdings of currency 1 in the next period, where the money growth rate $\gamma_{1}$ appears because we normalize nominal quantities and prices associated with currency 1 by $M_{1}$. This amount of holdings comes from the holdings after the currency trade in this period (the first group of terms), minus the spending by the buyers (the second group of terms), plus the amount of currency 1 received by the household's sellers (the third group of terms), and plus the transfers of currency 1 received at the beginning of the next period. Similarly, (2.9) describes the law of motion of holdings of money 2. Its main difference from (2.8) is that a country 1 household does not receive transfers of currency 2.

\section{Equilibrium}

\subsection{Definition}

A monetary equilibrium consists of the representative households' decisions $\left(h_{1}, h_{2}\right)$, other households' decisions $\left(H_{1}, H_{2}\right)$, and the nominal exchange rate $e$ such that the following requirements are met for all $t$ : (i) Given $\left(e, H_{1}, H_{2}\right)$ and other aggregate variables, $h_{1}$ solves $(P H)$ and $h_{2}$ solves a similar problem for a country 2's household; (ii) The decisions are symmetric within each country: $h_{i}=H_{i}$ for $i=1,2$; (iii) The currency market clears: $f_{22}=e f_{11}$; (iv) Money holdings 
add up: $m_{1 k}+m_{2 k}=1$, for $k=1,2$; and (v) Both currencies have positive and bounded value: $0<\omega_{1 i} m_{1 i}+\omega_{2 i} m_{2 i}<\infty$ for $i=1,2$.

Under symmetry within each country, we have $N_{i i}=n_{i}, N_{i i^{\prime}}=1-n_{i}, S_{i i}=s$, and $S_{i i^{\prime}}=1-s$ for $i=1,2$ and $i^{\prime} \neq i$. Thus, the total number of buyers in currency area $i$ is $\left(n_{i}+1-n_{i^{\prime}}\right)$ and the total number of sellers in area $i$ is $(s+1-s)=1$. However, we do not impose symmetry between the two countries' decisions. In particular, we do not require $n_{1}=n_{2}$.

\subsection{Equilibrium Conditions}

To characterize optimal decisions, let $\lambda_{i k}$ be the shadow price of the money constraint faced by a country $i$ buyer in a trade with a domestic seller in area $k$, and $\lambda_{i k}^{f}$ be the shadow price in a trade in area $k$ with a foreign seller. For example, $\lambda_{11}$ is the shadow price of the first constraint in (2.6) and $\lambda_{11}^{f}$ of the second constraint. These shadow prices are the non-pecuniary returns to the currencies generated by relaxing the trade restrictions. It is convenient to rescale each of these multipliers by the number of the corresponding type of trade matches that the household has. That is, $\lambda_{i i}$ is multiplied by $n_{i} T_{i i}^{i} / N_{i}, \lambda_{i i}^{f}$ by $n_{i} T_{i i^{\prime}}^{i} / N_{i}, \lambda_{i i^{\prime}}$ by $\left(1-n_{i}\right) T_{i i}^{i^{\prime}} /\left(1-N_{i}\right)$, and $\lambda_{i i^{\prime}}^{f}$ by $\left(1-n_{i}\right) T_{i i^{\prime}}^{i^{\prime}} /\left(1-N_{i}\right)$, where $i^{\prime} \neq i$.

The following conditions are necessary for the decisions to be optimal.

(i) On the trading quantities $\left(x_{i k}, q_{i k}\right)$ and $\left(x_{i k}^{f}, q_{i k}^{f}\right)$ :

$$
\begin{aligned}
& A=\left(\omega_{i k}+\lambda_{i k}\right) \frac{\sigma\left(q_{i k}\right)^{\sigma-1}}{\Omega_{i k}}, \\
& A=\left(\omega_{i k}+\lambda_{i k}^{f}\right) \frac{\sigma\left(q_{i k}^{f}\right)^{\sigma-1}}{\Omega_{i^{\prime} k}} .
\end{aligned}
$$

Since the two equations are similar, we explain the first one only. The left-hand side of the equation is the marginal utility of consumption, and hence the marginal benefit of an additional unit of good to a buyer. The right-hand side is the cost to a country $i$ buyer of asking a country $i$ seller in area $k$ to supply an additional unit of good. To obtain the additional unit of good, the buyer must offer $\sigma\left(q_{i k}\right)^{\sigma-1} / \Omega_{i k}$ units of currency $k$ (see (2.4)). The cost of giving up one unit of currency $k$ is the sum of the future marginal value of the currency, $\omega_{i k}$, and the shadow price of the trading restriction on the currency, $\lambda_{i k}$.

(ii) On the choice of $n_{i}$ (the fraction of buyers of country $i$ sent to area $i$ ):

$$
\frac{T_{i i}^{i}}{N_{i}} A q_{i i}+\frac{T_{i i^{\prime}}^{i}}{N_{i}} A q_{i i}^{f}=\frac{T_{i i}^{i^{\prime}}}{1-N_{i}} A q_{i i^{\prime}}+\frac{T_{i i^{\prime}}^{i^{\prime}}}{1-N_{i}} A q_{i i^{\prime}}^{f}, i^{\prime} \neq i
$$


By sending one additional buyer to currency $i$, the household obtains more consumption goods from area $i$, which increases the household's utility by the amount given by the left-hand side. The cost is that the household must reduce the number of buyers sent to area $i^{\prime}$ by one, which reduces the utility of consumption by the amount given by the right-hand side. These marginal benefits and costs must equal each other when an interior value of $n_{i}$ is optimal. ${ }^{10}$

(iii) On the amounts of currency exchanges, $f_{11}$ and $f_{22}$ :

$$
\begin{aligned}
& \omega_{11}+\frac{T_{11}^{1}}{N_{1}} \lambda_{11}+\frac{T_{12}^{1}}{N_{1}} \lambda_{11}^{f}=\left(\omega_{12}+\frac{T_{11}^{2}}{1-N_{1}} \lambda_{12}+\frac{T_{12}^{2}}{1-N_{1}} \lambda_{12}^{f}\right) e \\
& \omega_{21}+\frac{T_{22}^{1}}{1-N_{2}} \lambda_{21}+\frac{T_{21}^{1}}{1-N_{2}} \lambda_{21}^{f}=\left(\omega_{22}+\frac{T_{22}^{2}}{N_{2}} \lambda_{22}+\frac{T_{21}^{2}}{N_{2}} \lambda_{22}^{f}\right) e .
\end{aligned}
$$

Since these two conditions are similar, we explain only the first one by considering a country 1 household's choice of $f_{11}$. By increasing $f_{11}$ by one unit, the household reduces the total amount of currency 1 by one unit and increases the total amount of currency 2 by $e$ units. The expected values of these two amounts of currencies, given by the two sides of (3.4), must be equal to each other. Note that the value of a currency before matches take place consists of the future value of the currency, $\omega$, and the expected non-pecuniary returns that the currency can generate by relaxing the money constraints in trade matches.

(iv) On money holdings, $m_{i i}$ and $m_{i i^{\prime}}$ (the envelope conditions):

$$
\begin{aligned}
& \omega_{i i,-1}=\frac{\beta}{\gamma_{i}}\left(\omega_{i i}+\frac{T_{i i}^{i}}{N_{i}} \lambda_{i i}+\frac{T_{i i^{\prime}}^{i}}{N_{i}} \lambda_{i i}^{f}\right) \\
& \omega_{i i^{\prime},-1}=\frac{\beta}{\gamma_{i^{\prime}}}\left(\omega_{i i^{\prime}}+\frac{T_{i i}^{i^{\prime}}}{1-N_{i}} \lambda_{i i^{\prime}}+\frac{T_{i i^{\prime}}^{i^{\prime}}}{1-N_{i}} \lambda_{i i^{\prime}}^{f}\right) .
\end{aligned}
$$

We explain the first condition only. The left-hand side of (3.6) is the marginal value of currency $i$ in the current period to a country $i$ household. The right-hand side is the discounted value of currency $i$ in the next period plus the expected non-pecuniary return that the currency can generate in the current period. The condition (3.6) says that the rate of non-pecuniary return to currency $i$ must be equal to the nominal interest rate, which is given by $\gamma_{i} / \beta$.

\footnotetext{
${ }^{10}$ Strictly speaking, (3.3) is the result of combining these benefits and costs with those arising from the change in the amount of money spent. By increasing $n_{i}$, the household bears the expected cost of money spent by the additional buyer in currency area $i$, which is equal to $\frac{T_{i i}^{i}}{N_{i}}\left(\omega_{i i}+\lambda_{i i}\right) x_{i i}+\frac{T_{i i}^{i}}{N_{i}}\left(\omega_{i i}+\lambda_{i i}^{f}\right) x_{i i}^{f}$. By the optimal condition for $\left(x_{i k}, q_{i k}\right)$, this amount is equal to $\frac{1}{\sigma}$ times the amount given by the left-hand side of (3.3). Similarly, the expected gain from the savings of money in currency area $i^{\prime}$ as a result of reducing $\left(1-n_{i}\right)$ is $\frac{1}{\sigma}$ times the amount given by the right-hand side of (3.3). After combining these costs and benefits with the ones in (3.3), we can eliminate the coefficient $\left(1-\frac{1}{\sigma}\right)$.
} 


\subsection{Characterizing a Stationary Equilibrium}

We set the growth rate of each currency to be constant, i.e., $\gamma_{k t}=\gamma_{k}$ for all $t$. This enables us to focus on the stationary equilibrium. In such an equilibrium, $h_{i,+1}=h_{i}$ and $\omega_{i k,+1}=\omega_{i k}$ for all $i$ and $k$, where $h_{i}$ is the list of a country $i$ household's choices. Also, we restrict $\gamma_{1}>\beta$ and $\gamma_{2}>\beta$, so that all money constraints in trade bind (see the analysis later), i.e., all $\lambda$ 'es are positive.

The stationary equilibrium has the following properties regarding relative quantities and prices. First, each country's relative valuation of the two currencies must be equal to the nominal exchange rate:

$$
\frac{\gamma_{1}}{\gamma_{2}} \frac{\omega_{11}}{\omega_{12}}=e=\frac{\gamma_{1}}{\gamma_{2}} \frac{\omega_{21}}{\omega_{22}}
$$

This result comes from the conditions for optimal currency exchanges, (3.4) and (3.5), and the envelope conditions for money holdings. Here, we have used the requirement for stationarity: $e_{+1}=e$. The above condition is necessary and sufficient for eliminating arbitrage in the currency market. For example, if $\gamma_{1} \omega_{11} /\left(\gamma_{2} \omega_{12}\right)<e$, then a household in country 1 could gain by selling more currency 1 for currency 2 in the currency market.

Second, the above condition implies that the relative valuation of a currency between the two countries is the same for the two currencies. Denote this relative valuation as

$$
\theta=\frac{\omega_{11}}{\omega_{21}}=\frac{\omega_{12}}{\omega_{22}}
$$

Also, denote $\theta_{1}=\theta$ and $\theta_{2}=1 / \theta$. In general, $\theta \neq 1$. That is, the two countries do not value the same currency to the same level. If a country values one currency more than the other country, it also values the other currency more. For example, when $\theta>1$, country 1 households value both currencies more highly than country 2 households. This cross-country difference in the valuation of the currencies is sustained by the inability to arbitrage instantaneously between the goods markets and the currency market.

Third, after controlling for the currency used, the relative quantity of goods that a buyer obtains from a country 1 seller to that from a country 2 seller is the same in the two areas and the same for the two countries' buyers. Using the binding money constraints and the sellers' participation constraints, we can link this relative quantity to $\theta$ as follows:

$$
\frac{q_{11}}{q_{11}^{f}}=\frac{q_{12}}{q_{12}^{f}}=\frac{q_{21}^{f}}{q_{21}}=\frac{q_{22}^{f}}{q_{22}}=\theta^{1 / \sigma} .
$$


If $\theta \neq 1$, then there is a quantity differential between the two countries' sellers even after controlling for the currency used. For example, if $\theta>1$, then a country 1 seller sells more goods for the same type and amount of currency than a country 2 seller does. This result is intuitive because, when $\theta>1$, money is more valuable to a country 1 seller's household than to a country 2 seller's household. As we will show later, this quantity differential implies a price differential in each area and the failure of the law of one price.

Fourth, there is a differential in the quantity of goods that a buyer gets in the two areas. To see this, solve the $\lambda$ 'es from (3.1) and (3.2) and use (3.8) - (3.10) to express the solutions are functions of $(q, \theta)$. Then, (3.6) and (3.7) imply the following equations where $i^{\prime} \neq i$ and $i, i^{\prime}=1,2$ :

$$
\begin{aligned}
& q_{i i}=\left[\left(\frac{A}{\sigma}\right) \frac{s+(1-s) \theta_{i}^{-1 / \sigma}}{1+\left(\frac{\gamma_{i}}{\beta}-1\right) / \mu\left(n_{i}\right)}\right]^{\frac{1}{\sigma-1}}, \\
& q_{i i^{\prime}}=\left[\left(\frac{A}{\sigma}\right) \frac{(1-s)+s \theta_{i}^{-1 / \sigma}}{1+\left(\frac{\gamma_{i^{\prime}}}{\beta}-1\right) / \mu\left(1-n_{i}\right)}\right]^{\frac{1}{\sigma-1}} .
\end{aligned}
$$

As defined before, $\mu(n)=L(n) / n, \theta_{1}=\theta$ and $\theta_{2}=1 / \theta$. The ratio $q_{i i} / q_{i i^{\prime}}$ is the relative quantity of goods that a county $i$ buyer gets from a country $i$ seller in the two currency areas. Note that this relative quantity is independent of the seller whom the buyer meets, as required by (3.10). That is, $q_{11} / q_{12}=q_{11}^{f} / q_{12}^{f}$ and $q_{21}^{f} / q_{22}^{f}=q_{21} / q_{22}$.

Finally, the equilibrium satisfies the following lemma (see Appendix A for a proof):

Lemma 3.1. In the stationary equilibrium, $n_{2}=1-n_{1}$. If $\gamma_{1}=\gamma_{2}=\gamma$, then $\theta=1, n_{1}=n_{2}=$ $1 / 2$ and $q_{i j}=q_{i j}^{f}=\mathcal{Q}(\gamma)$ for all $i, j=1,2$, where

$$
\mathcal{Q}(\gamma) \equiv\left(\frac{A / \sigma}{1+\left(\frac{\gamma}{\beta}-1\right) / \mu\left(\frac{1}{2}\right)}\right)^{\frac{1}{\sigma-1}}
$$

The two countries allocate the same fraction of buyers to a currency area. This result arises from the property that the two countries have the same relative valuation of the two currencies. For example, if it is optimal for a household in country 1 to allocate more than a half of the buyers to area 1, it must be the case the household values currency 1 more than currency 2 . Because the equilibrium in the currency market ensures that the two countries have the same relative valuation of the two currencies, a household in country 2 also values currency 1 more 
than currency 2 in this case. Hence, it is also optimal for a country 2 household to allocate more than a half of the buyers to area 1.

The result $n_{2}=1-n_{1}$ depends on the assumption that the matching process is asymmetric between the two countries. For example, if $\psi=1$, then the allocation of buyers to the two areas would be immaterial for the household's optimization. In this case, there would be no relationship between $n_{1}$ and $n_{2}$. Similarly, if the matching function were $L\left(N_{1 i}+N_{2 i}\right) S_{i}$ for area $i$, then the allocation of buyers to the two areas would not matter for a household even if $\psi<1$.

Note that the feature $n_{2}=1-n_{1}$ implies the following result from (3.11) and (3.12):

$$
\frac{q_{21}}{q_{11}}=\frac{q_{22}}{q_{12}}=\theta^{1 /[\sigma(\sigma-1)]}
$$

That is, the relative quantity of goods that the two countries' buyers get from their domestic sellers is independent of the area in which they buy. This relative quantity is a function of the two countries' relative valuation of a currency.

Lemma 3.1 also states that all differences between the two countries in the equilibrium allocation are driven by the difference between the growth rates of the two currencies. If the two currencies have the same growth rate, then each country will allocate exactly a half of the buyers to each area and agents will trade the same quantity of goods in all trade matches. This will be true despite the existence of the two other differences between the two countries in the physical environment, i.e., the possibility of $s>1 / 2$ and asymmetric monetary transfers. We will explain this result later after Lemma 4.2 .

Determining the equilibrium amounts to solving for $\left(n_{1}, \theta\right)$. In Appendix A, we show that $n_{1}$ and $\theta$ solve the following two equations:

$$
\begin{aligned}
& \frac{1-s+s \theta^{1 / \sigma}}{s+(1-s) \theta^{1 / \sigma}}=\left[\frac{\mu\left(1-n_{1}\right)}{\mu\left(n_{1}\right)}\right]^{1-\frac{1}{\sigma}}\left[\frac{\left(\frac{\gamma_{1}}{\beta}-1\right) / \mu\left(n_{1}\right)+1}{\left(\frac{\gamma_{2}}{\beta}-1\right) / \mu\left(1-n_{1}\right)+1}\right]^{\frac{1}{\sigma}}, \\
& \theta^{\frac{\sigma}{\sigma-1}}=\frac{\left[\left(\gamma_{2}-1\right)\left(1-n_{1}\right)+s\left(1-n_{1}\right) \mu\left(1-n_{1}\right)\right]\left[G\left(n_{1}, \theta\right)\right]^{\sigma}+(1-s) n_{1} \mu\left(n_{1}\right)}{\left(\gamma_{1}-1\right) n_{1}+s n_{1} \mu\left(n_{1}\right)+(1-s)\left(1-n_{1}\right) \mu\left(1-n_{1}\right)\left[G\left(n_{1}, \theta\right)\right]^{\sigma}}
\end{aligned}
$$

where

$$
G\left(n_{1}, \theta\right) \equiv \frac{\mu\left(n_{1}\right)}{\mu\left(1-n_{1}\right)}\left[\frac{1-s+s \theta^{1 / \sigma}}{s+(1-s) \theta^{1 / \sigma}}\right] .
$$


In the derivation of (3.16), we have used the result $n_{2}=1-n_{1}$ and hence the assumption $\psi<1$. If $\psi=1$, instead, then (3.16) would involve both $n_{1}$ and $n_{2}$; in this case, there would not be enough equations to determine $n_{1}$ and $n_{2}$ uniquely.

Once $n_{1}$ and $\theta$ are determined, other variables can be determined accordingly. In particular, from (3.8), (2.6) and (2.7), we can obtain the nominal exchange rate as follows:

$$
e=\frac{\gamma_{1}}{\gamma_{2}} \frac{n_{1}}{1-n_{1}} /\left[G\left(n_{1}, \theta\right)\right]^{\sigma} .
$$

\section{Integrated Economy}

For general values of $s$, it is difficult to establish analytically the existence and uniqueness of the solutions for $n_{1}$ and $\theta$. However, the solution does exist and is unique for an integrated economy, i.e., for $s=1 / 2$. In this and the next section, we will focus on this case. The focus enables us to obtain sharp predictions on the effects of inflation and optimal monetary policy. In section 6 , we will use numerical examples to illustrate the robustness of the results to changes in $s$. The proofs for this section are collected in Appendix B.

\subsection{Determination of the Equilibrium and the Size of a Currency Area}

In the integrated economy $(s=1 / 2),(3.15)$ is simplified to

$$
\left[\frac{\mu\left(n_{1}\right)}{\mu\left(1-n_{1}\right)}\right]^{\sigma-1}=\frac{1+\left(\frac{\gamma_{1}}{\beta}-1\right) / \mu\left(n_{1}\right)}{1+\left(\frac{\gamma_{2}}{\beta}-1\right) / \mu\left(1-n_{1}\right)} .
$$

Once $n_{1}$ is solved from this equation, $\theta$ is given uniquely by (3.16), and hence the stationary equilibrium exists. The following proposition describes the solution for $n_{1}$.

Proposition 4.1. Denote $\mathcal{D}=\left\{\left(\gamma_{1}, \gamma_{2}\right): \gamma_{i}<\left(\beta L_{0}+\gamma_{i^{\prime}}-\beta\right) / L_{0}^{\sigma}\right\}$. A unique equilibrium exists, provided $\gamma_{1}, \gamma_{2} \in \mathcal{D}$. Denote this equilibrium value of $n_{1}$ as $n_{1}=N\left(\gamma_{1}, \gamma_{2}\right)$. Then, $N_{1}\left(\gamma_{1}, \gamma_{2}\right)<0$ and $N_{2}\left(\gamma_{1}, \gamma_{2}\right)>0$. Moreover, $N(\gamma, \gamma)=1 / 2$ for all $\gamma>\beta$, and $N\left(\gamma_{1}, \gamma_{2}\right)>1 / 2$ iff $\gamma_{1}<\gamma_{2}$.

The allocation of the buyers to the two areas is unique in the equilibrium. This is not an obvious result given our assumption that the two countries' goods are perfect substitutes. If the markets for goods were Walrasian, then any choice $n_{1} \in[0,1]$ would generate the same amount of consumption and the same cost of production. Indeterminacy also arises if the matching process 
is symmetric between the two countries. Only when the matching process is asymmetric does the number of trades depend on the allocation of buyers to the two areas. In this case, there is a unique allocation of buyers to the two areas that maximizes a household's expected gain from trading in the two areas.

The allocation of buyers to the two areas depends on money growth rates in an intuitive way. When the growth rate of currency 1 is higher than that of currency 2, all households send fewer buyers to area 1 and more to area 2. This re-allocation of buyers arises from the effect of money growth on $\theta$, the valuation of currencies of a country 1 household relative to that of a country 2 household. As we will explain in section 4.3, $\theta<1$ when $\gamma_{1}>\gamma_{2}$. Then, as indicated by (3.10), a buyer obtains more goods from trading with a country 2 seller than with a country 1 seller. Given this quantity differential, it is beneficial for a country 1 household to reduce the frequency of purchases from domestic sellers and increase the frequency from foreign sellers. The household can achieve this outcome only by sending more buyers to area 2 . The same re-allocation of buyers is beneficial for a country 2 household.

The response of $n$ to money growth affects the size of a currency area. We measure the size of a currency area by the total number of trades that take place in the area in each period. ${ }^{11}$ Then, the size of currency area $k$ is:

$$
T_{11}^{k}+T_{12}^{k}+T_{21}^{k}+T_{22}^{k}=2 n_{k} \mu\left(n_{k}\right), \quad k=1,2
$$

The equality comes from the result $1-n_{2}=n_{1}$. Because $n \mu(n)$ increases in $n$, the dependence of $n$ on money growth rates implies that a currency area shrinks with the growth rate of the currency used in the area and expands with the growth rate of the competing currency. Only when the two currencies have the same growth rate do the two areas have the same size.

\subsection{The Nominal Exchange Rate}

When $s=1 / 2$, the condition that determines the nominal exchange rate, (3.18), becomes:

$$
e=\left(\frac{\gamma_{1}}{\gamma_{2}}\right) \frac{n_{1}}{1-n_{1}}\left[\frac{\mu\left(1-n_{1}\right)}{\mu\left(n_{1}\right)}\right]^{\sigma}
$$

Because $n_{1}$ is uniquely determined in the equilibrium, the nominal exchange rate is also determinate. As a result, the net amount of currency trade, the portfolio of money holdings and the

\footnotetext{
${ }^{11}$ Another way to measure the size of a market is to use the aggregate transaction value in goods market. This measure is more complicated to compute because all four types of trade in an area result in different quantities of goods traded. However, the results are similar.
} 
quantities of goods traded in matches are all determined uniquely (see section 3).

Moreover, the nominal exchange rate depends on the levels and growth rates of the two currencies in intuitive ways. Recall that $e$ is the nominal exchange rate normalized by the ratio of the stocks of the two currencies. Without normalization, the nominal exchange rate is $e M_{2} / M_{1}$. Thus, when $\gamma_{1}>\gamma_{2}$, currency 1 depreciates against currency 2 over time and the rate of depreciation is equal to $\left(\gamma_{1}-\gamma_{2}\right)$. After the normalization, the exchange rate, $e$, is stationary. Clearly, $e=1$ if and only if the two currencies grow at the same rate. For $\gamma_{1} \neq \gamma_{2}$, the normalized exchange rate decreases in $\gamma_{1}$ and increases in $\gamma_{2}$, with $e>1$ if and only if $\gamma_{1}<\gamma_{2}$ (see the proof of Lemma 4.2 later).

The determinacy of the exchange rate can be linked to the allocation of buyers to the two areas. For each country, the allocation of buyers generates a relative valuation of the two currencies. But this relative valuation must be equal between the two countries in order to prevent profitable arbitrage in the currency market. Only a particular nominal exchange rate can achieve this equilibrium. Since the asymmetry in the matching process is important for uniquely determining the allocation of buyers, it is also important for the determinacy of the exchange rate. In contrast, the assumption of a fixed $s$ is not particularly important for such determinacy.

Another important assumption for the determinacy of the exchange rate is that a buyer cannot use two currencies to buy goods in the same trade. As in Head and Shi (2003), this assumption rules out the type of indeterminacy in Kareken and Wallace (1981). In the latter, the nominal exchange rate without normalization is fixed at an arbitrary level, which implies that the normalized exchange rate grows at the rate $\left(\gamma_{1}-\gamma_{2}\right)$. We can show that such equilibria do not exist in the current model.

\subsection{Cross-Country Difference in the Valuation of Currencies}

An important variable in the equilibrium is country 1's valuation of a currency relative to country 2's, denoted $\theta$ in the above analysis and given by (3.16). The following lemma describes the properties of $\theta$.

Lemma 4.2. If $\gamma_{1}=\gamma_{2}$, then $\theta=1$. If $\gamma_{2} \leq 1$, then $\theta>1$ for all $\beta<\gamma_{1}<\gamma_{2}$. If $\gamma_{2}>1$, then there exists $\gamma_{0} \in\left(1, \gamma_{2}\right]$ such that $\theta>1$ for all $\beta<\gamma_{1}<\gamma_{0}$. 
This lemma says that, when money growth rates are not very high, a country 1 household has higher valuation for both currencies than a country 2 household if and only if the growth rate of currency 1 is lower than that of currency 2. The cause of this result is that a household receives only domestic monetary transfers. To ease the explanation, suppose $\gamma_{1}>1$ and $\gamma_{2}>1$ so that the transfers are positive. Each country's households want to sell part of the received transfers for the other country's currency. If $\gamma_{1}=\gamma_{2}$, then the transfers of the two currencies have the same real value. In this case, a household sells exactly a half of the received transfers for the other country's currency. As a result, each country holds a half of the stock of each currency, and the households in the two countries have the same valuation of each currency. In contrast, if $\gamma_{2}>\gamma_{1}$ and if $\gamma_{2}$ is not very high, then the real value of currency 2 transfers exceeds that of currency 1 transfers. Country 1 households sell more than a half of the received transfers for currency 2. As a result, country 1 households hold less than a half of the stock of each currency and they value both currencies more than country 2 households. ${ }^{12}$

The currency market cannot eliminate the difference between the two countries' valuations of a currency; rather, it equalizes only the relative valuation of the two currencies between the two countries. If a household in country 1 values one currency more than a household in country 2 , it also values the other currency more. To reduce this gap between the two countries' valuations of currency 1, a household in country 1 would have to buy more of the first currency and sell more of currency 2 in the currency market than it does in the described equilibrium. But this would widen the gap between the two countries' valuations of currency 2. One way to eliminate the gap is to trade goods for currencies in the currency market, but this action is not available in the described environment.

It is also worth mentioning that the trade of goods for money in the goods markets cannot replicate the missing trade of goods for money in the centralized currency market. The former is fragmented as a result of bilateral matches and cannot ensure uniform prices in different types of matches. We now turn to these price differentials.

\footnotetext{
${ }^{12}$ The result may be reversed when $\gamma_{2}$ is very high and when $\gamma_{1}$ is close to $\gamma_{2}$. With a very high growth rate, the inflation effect is so overwhelming that the real value of currency 2 transfers is lower than that of currency 1 , despite the amount of currency 2 transfers is higher. In this case, country 1 households are able to buy more than a half of currency 2 transfers with less than a half of currency 1 transfers. As a result, country 1 households value both currencies less than country 2 households.
} 


\subsection{Relative Prices}

In section 3, we showed that there are various quantity differentials in the goods market. Now we show that these differentials imply price differentials and, hence, failures of the law of one price.

Let us define prices. In a currency area $k$, there are four types of trades and hence four prices, two for each country's buyers. Fix the buyer's country index $i$. The price implied by a trade with a domestic seller, $p_{i k}$, and the price implied by a trade with a foreign seller, $p_{i k}^{f}$, are

$$
p_{i k}=\frac{\widehat{m}_{i k}}{n_{i k} q_{i k}}, \quad p_{i k}^{f}=\frac{\widehat{m}_{i k}}{n_{i k} q_{i k}^{f}},
$$

where $\widehat{m}_{i k}$ is the amount of currency $k$ that a country $i$ household has after the trade in the currency market. For example, $\widehat{m}_{11}=m_{11}-f_{11}$ and $\widehat{m}_{12}=m_{12}+e f_{11}$. Since $\widehat{m}_{i k}$ is normalized by the total stock of currency $k$, prices defined above are also normalized.

We can compute the relative price charged by the two countries' sellers when selling to the same country's buyers in the same currency area. There are four such relative prices, but they are all equal to a common value denoted $R_{1}$ :

$$
R_{1}=\frac{p_{11}}{p_{11}^{f}}=\frac{p_{12}}{p_{12}^{f}}=\frac{p_{21}^{f}}{p_{21}}=\frac{p_{22}^{f}}{p_{22}} .
$$

The equalities come from (3.10). Similarly, we can compute the relative price paid by the two countries' buyers when buying from the same sellers in the same currency area. There are four such relative prices, which are equal to a common value denoted $R_{2}$ :

$$
R_{2}=\frac{p_{11}}{p_{21}^{f}}=\frac{p_{12}}{p_{22}^{f}}=\frac{p_{11}^{f}}{p_{21}}=\frac{p_{12}^{f}}{p_{22}} .
$$

Using (3.10) and (3.14), it is easy to establish the following corollary (the proof is omitted):

Corollary 4.3. For all $s \in[0.5,1], R_{1}=\theta^{-1 / \sigma}$ and $R_{2}=\theta^{-1}$ in the stationary equilibrium.

The law of one price fails when $\theta \neq 1$, i.e., when the two currencies have different growth rates. For example, when currency 1 has a higher growth rate than currency 2, the households in country 1 value each currency less than the households in country 2, i.e. $\theta<1$. As a result, country 1's sellers charge higher prices than country 2's sellers when selling to the same buyers in the same currency area, and country 1's buyers pay higher prices than country 2's buyers when buying from the same sellers in the same currency area. Therefore, by changing its money growth, a country can affect the relative quantity and prices between different types of trade. 


\section{Optimal Monetary Policy}

Now we examine the countries' choices of long-run money growth rates $\left(\gamma_{1}, \gamma_{2}\right)$ under two institutional regimes: the noncooperative regime and the cooperative regime. The noncooperative regime is also referred to as policy competition. At the end of this section, we will remark on the outcome under a unified currency. Only the integrated economy, $s=1 / 2$, is analyzed in this section and all proofs are collected in Appendix C.

\subsection{Noncooperative Monetary Policy}

Under noncooperative policy, each country takes the growth rate of the other country's currency as given and chooses its money growth rate to maximize the country's own welfare. ${ }^{13}$ We measure a country's welfare with the steady state utility, per period, of the country's representative household. Denote this welfare measure for country $i$ as $W_{i}=(1-\beta) v\left(m_{i 1}, m_{i 2}\right)$. Then,

$$
\begin{aligned}
W_{i}= & A\left(T_{i i}^{i} q_{i i}+T_{i i^{\prime}}^{i} q_{i i}^{f}\right)+A\left(T_{i i}^{i^{\prime}} q_{i i^{\prime}}+T_{i i^{\prime}}^{i^{\prime}} q_{i i^{\prime}}^{f}\right) \\
& -\left[T_{i i}^{i}\left(q_{i i}\right)^{\sigma}+T_{i^{\prime} i}^{i}\left(q_{i^{\prime} i}^{f}\right)^{\sigma}\right]-\left[T_{i i}^{i^{\prime}}\left(q_{i i^{\prime}}\right)^{\sigma}+T_{i^{\prime} i}^{i^{\prime}}\left(q_{i^{\prime} i^{\prime}}^{f}\right)^{\sigma}\right] .
\end{aligned}
$$

The first two groups of terms on the right-hand side are total utility of consumption and the last two groups of terms are disutility of production. After substituting the equilibrium quantities, $W_{i}$ is a function of $\left(\gamma_{1}, \gamma_{2}\right)$.

We use the so-called Friedman rule, $\gamma=\beta$, as the reference point because this rule is often optimal in a closed economy. Supposing that one country fixes the growth rate of its currency at the Friedman rule, we examine whether the other country can gain from a unilateral deviation from the Friedman rule. ${ }^{14}$ The following proposition describes the result.

Proposition 5.1. Given $\gamma_{i^{\prime}}=\beta\left(i^{\prime} \neq i\right)$, country $i$ 's policy has the following effects near $\gamma_{i}=\beta$ : $d n_{i} / d \gamma_{i}<0, d \theta_{i} / d \gamma_{i}<0$ and $d W_{i} / d \gamma_{i}>0$, where $\theta_{1}=\theta$ and $\theta_{2}=1 / \theta$.

One country can increase its welfare by increasing its money growth rate above the Friedman rule if the other country follows the Friedman rule. This gain is redistributive because it comes at the expense of the other country. To explain the gain, recall that monetary transfers are

\footnotetext{
${ }^{13} \mathrm{As}$ is common in the literature, the game is a one-shot game. In particular, we do not allow for trigger strategies. As is well known in game theory, allowing for trigger strategies generates a large set of equilibria, since any individually rational outcome can be supported by trigger strategies in an infinitely repeated game.

${ }^{14}$ In this paper, we refer to the Friedman rule as the limit $\gamma \downarrow \beta$, because we have imposed $\gamma_{1}>\beta$ and $\gamma_{2}>\beta$ to ensure that all money contraints in trade bind.
} 
made only to domestic households. When country 1 sets its money growth rate above country 2's, country 1 households will end up having more of each currency than country 2 households (see the explanation for Lemma 4.2). This redistribution of money holdings increases country 1 households' purchasing power relative to country 2 households. More precisely, the redistributive effect works through $\theta$. When $\gamma_{1}$ is higher than $\gamma_{2}$, the resulted higher holdings of money by country 1 households depress their valuation of the currencies relative to country 2 households. That is, $\theta$ falls below one. This change in the relative valuation enables a buyer to buy more from a country 2 seller than from a country 1 seller (see (3.10)). Thus, utility increases in country 1 and decreases in country 2. As we will illustrate in section 7 , this redistributive effect of inflation is significantly different from the classic effect of "beggar-thy-neighbour".

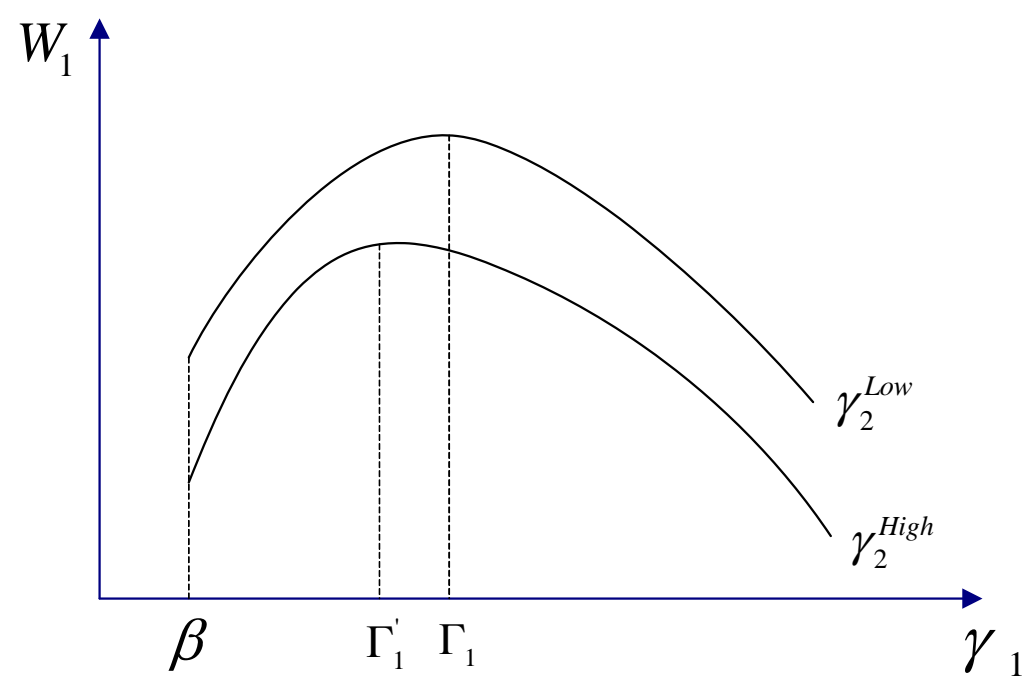

Figure 4. Country 1's welfare under two given values of $\gamma_{2}$

There are two remarks on the redistributive effect. First, the redistributive gain from increasing the growth rate of a currency comes with a reduction in the size of the area marked with that currency. That is, $d n_{i} / d \gamma_{i}<0$. This effect comes from the effect of money growth on $\theta$, as it was explained in section 4.1. Second, there is a tendency for prices to respond to inflation so as to reduce the redistributive gain. For example, when currency 1 has a higher growth rate than currency 2, all sellers charge higher prices to country 1 buyers than to country 2 buyers. However, this price disadvantage does not wipe out the redistributive gain to country 1 .

Proposition 5.1 implies that the Friedman rule cannot be a Nash equilibrium under policy competition. To determine the Nash equilibrium, we need to examine the best response of one 
country's money growth to any arbitrarily given growth rate of the other currency, not just the best response to the Friedman rule. When the other country does not follow the Friedman rule, the redistributive effect of inflation described above still exists. But there is also a negative effect of inflation, because inflation reduces the purchasing power of the portfolio of currencies. The overall effect of inflation on a country's welfare depends on the balance of the two opposing effects. Figure 4 depicts this overall effect of $\gamma_{1}$ on country 1's welfare under two values of $\gamma_{2}$. For each value of $\gamma_{2}$, country 1's welfare first increases in $\gamma_{1}$, reaches a peak at some level $\Gamma_{1}$, and then decreases in $\gamma_{1}$ when $\gamma_{1}>\Gamma_{1}$. Thus, the best response of $\gamma_{1}$ to $\gamma_{2}$ is always above the Friedman rule and is finite.

Note that the best response of $\gamma_{1}$ to $\gamma_{2}$ is lower when $\gamma_{2}$ is higher. This feature of the best response implies that country 1's incentive to inflate is the highest when country 2 follows the Friedman rule. It also suggests that a Nash equilibrium may exist. The following proposition describes the existence. ${ }^{15}$

Proposition 5.2. Assume $\beta>1-\mu\left(\frac{1}{2}\right)$. A Nash equilibrium exists, which features $\gamma_{1}^{*}=\gamma_{2}^{*}=$ $\gamma^{*}>\beta$.

\subsection{Monetary Policy under Coordination}

Under policy coordination or cooperation, the two countries choose growth rates of the two currencies jointly to maximize the world's aggregate welfare. Since the two countries are symmetric, we measure aggregate welfare by the average of the two countries' steady state utilities and denote it as $W^{c}=\frac{1}{2}\left(W_{1}+W_{2}\right)$, where $W_{i}$ is given by (5.1). The optimal monetary policy under the cooperative regime is a pair $\left(\gamma_{1}, \gamma_{2}\right)$ that maximizes $W^{c}$.

Because the two countries are symmetric, the optimal policy must have the same money growth rate of both currencies, say $\gamma$. By Lemma 3.1, then $\theta=1, n_{1}=n_{2}=1 / 2$, and $q_{i j}=q_{i j}^{f}=$ $\mathcal{Q}(\gamma)$ for all $i, j=1,2$, where $\mathcal{Q}(\gamma)$ is defined by $(3.13)$. Thus, $W^{c}=W(\gamma)$ where

$$
W(\gamma) \equiv 2 L\left(\frac{1}{2}\right)\left\{A \mathcal{Q}(\gamma)-[\mathcal{Q}(\gamma)]^{\sigma}\right\}
$$

Since the right-hand side is increasing in $\mathcal{Q}$ and $\mathcal{Q}$ is decreasing in $\gamma, W^{\prime}(\gamma)<0$. Thus, the optimal policy under cooperation is $\gamma_{1}=\gamma_{2}=\beta$, i.e., the Friedman rule for both currencies.

\footnotetext{
${ }^{15}$ It may be reasonable to conjecture that all Nash equilibria must have $\gamma_{1}=\gamma_{2}$, or that the equilibrium is unique under the restriction $\gamma_{1}=\gamma_{2}$. Although we have not found any numerical example that contradicts either conjecture, we are not able to establish the result analytically, because a country's best response is characterized by a complicated equation.
} 
It is not surprising that the Friedman rule is optimal under coordination. When the objective is to maximize aggregate welfare, the redistributive effect of inflation is irrelevant. The only effect to be considered is the negative effect of inflation in reducing the purchasing power of money. The Friedman rule minimizes this negative effect and, hence, maximizes aggregate welfare.

Not only does the cooperative regime generates higher aggregate welfare than the noncooperative regime, it also increases each country's welfare. That is, the cooperative outcome Pareto dominates the non-cooperative outcome. To see this, recall that the non-cooperative equilibrium generates $\gamma_{1}=\gamma_{2}=\gamma^{*}$. Thus, it has $\theta=1, n_{1}=n_{2}=1 / 2$, and $q_{i j}=q_{i j}^{f}=\mathcal{Q}\left(\gamma^{*}\right)$ for all $i, j=1,2$. As a result, each country's welfare level in the non-cooperative regime is given by the function $W\left(\gamma^{*}\right)$ defined above. Since $\gamma^{*}>\beta$, then $W\left(\gamma^{*}\right)<W(\beta)$.

The above analysis has established the following proposition.

Proposition 5.3. The optimal policy under coordination is the Friedman rule for both currencies. Welfare is higher for both countries under coordination than under no coordination.

The cooperative outcome is identical to that of the following regime of currency unification. Let each country receive a half of the transfers of the unified currency. Then, in the equilibrium, $n_{1}=n_{2}=1 / 2$ and each country holds a half of the money stock. As a result, $q_{i k}=q_{i k}^{f}=\mathcal{Q}(\gamma)$ for all $i, k=1,2$, where $\gamma$ is the growth rate of the unified currency. Then, the welfare level of each country is equal to $W(\gamma)$, which is maximized at $\gamma=\beta$. This optimal policy and the implied allocation are the same as those with policy coordination. Thus, we can view currency unification as a way to coordinate monetary policy between the countries.

\section{Not Fully Integrated Markets}

In this section we examine the case in which the two countries are not fully integrated, i.e., the case $s>1 / 2$. We analyze the non-cooperative regime, because the optimal policy under coordination is still the Friedman rule.

With $s>1 / 2$, a country's money growth generates a redistributive effect as in the benchmark case. In addition, money growth generates an extensive effect that affects the number of trades experienced by a household's sellers. To see this extensive effect, consider a country 1 household. The number of trades experienced by the household's sellers in a period is

$$
T_{1} \equiv T_{11}^{1}+T_{21}^{1}+T_{11}^{2}+T_{21}^{2}=2\left[n_{1} \mu\left(n_{1}\right) s+\left(1-n_{1}\right) \mu\left(1-n_{1}\right)(1-s)\right] .
$$


Start with $\gamma_{1}=\gamma_{2}$ so that $n_{1}=1 / 2$. A marginal increase in $\gamma_{1}$ affects $T_{1}$ as follows:

$$
\left.\frac{d T_{1}}{d \gamma_{1}}\right|_{\gamma_{1}=\gamma_{2}}=\left(s-\frac{1}{2}\right)\left[\mu\left(\frac{1}{2}\right)+\frac{1}{2} \mu^{\prime}\left(\frac{1}{2}\right)\right]\left(\frac{d n_{1}}{d \gamma_{1}}\right)_{\gamma_{1}=\gamma_{2}} .
$$

Note that $\mu(n)+n \mu^{\prime}(n)>0$ for all $n \in[0,1]$ and that $d n_{1} / d \gamma_{1}<0$ as in the benchmark case. Thus, for all $s>1 / 2$, an increase in the growth rate of currency 1 reduces the number of trades experienced by a country 1 household's sellers. As the country's sellers experience fewer trades, the disutility of production falls. That is, money growth generates a positive extensive effect on a country's welfare.

The effect of $\gamma_{1}$ on $T_{1}$ can be explained as follows. When $\gamma_{1}$ increases, $n_{1}$ falls. The number of trades experienced by sellers decreases in area 1 and increases in area 2 . The decrease in area 1 exceeds the increase in area 2 , because more than a half of the sellers in country 1 are in area 1. So, the total number of trades experienced by the sellers in a country 1 household falls. This change in the number of sellers' trades can be regarded as an externality, because it is generated by the change in the allocation of buyers to the two areas. Note that the total number of trades experienced by the household's buyers does not change when a country's money growth increases marginally above the other country's money growth. ${ }^{16}$

The effect of country 1's money growth on country 1's welfare can be decomposed as follows:

$$
q^{-\sigma} \frac{d W_{1}}{d \gamma_{1}}=\underbrace{\sigma \frac{2 s-1}{2 \beta(\sigma-1)}-\mu\left(\frac{1}{2}\right)\left[\frac{s^{2}+(1-s)^{2}}{\sigma-1}+1\right] \frac{d \theta}{d \gamma_{1}}}_{\text {redistributive effect }} \underbrace{-\frac{d T_{1}}{d \gamma_{1}}}_{\text {extensive effect }}
$$

Here, $q=\mathcal{Q}(\beta)$, and all the derivatives are evaluated at $\gamma_{1}=\gamma_{2}=\beta$. Note that the redistributive effect now contains not only the effect through $\theta$ but also a direct effect of money growth on the quantities of trade. When $s$ is close to $1 / 2$, the redistributive effect and the extensive effect of inflation are both positive. In this case, the Nash equilibrium under policy competition has $\gamma_{1}=\gamma_{2}>\beta$, as in the case $s=1 / 2$.

When the integration of the two countries is sufficiently low, the result is not so clear. To illustrate the result, we resort to numerical examples. Consider the following parameter values:

$$
\beta=0.995, A=4, \sigma=2, \psi=0.5
$$

With the particular value of $\beta$, the length of one period can be interpreted as one month. We start with three values of $s: 0.5,0.75$ and 1 . Fixing $\gamma_{2}=\beta$, we depict country 1 's welfare as a

\footnotetext{
${ }^{16}$ This can be verified by computing the buyers' number of trades as $2\left[n_{1} \mu\left(n_{1}\right)+\left(1-n_{1}\right) \mu\left(1-n_{1}\right)\right]$. Starting from any $\gamma_{1}=\gamma_{2}$ so that $n_{1}=1 / 2$, this number does not change with $n_{1}$ and hence not with $\gamma_{1}$.
} 
function of $\gamma_{1}$ in Figure 5. As in the benchmark case, a country's welfare depends on its money growth rate in a hump-shaped pattern. There is an incentive for each country to set its money growth rate above the Friedman rule. Note that the peak in Figure 5 occurs at higher levels of $\gamma_{1}$ when $s$ is smaller. This indicates that a country's incentive to inflate is higher when the two areas are more integrated with each other.

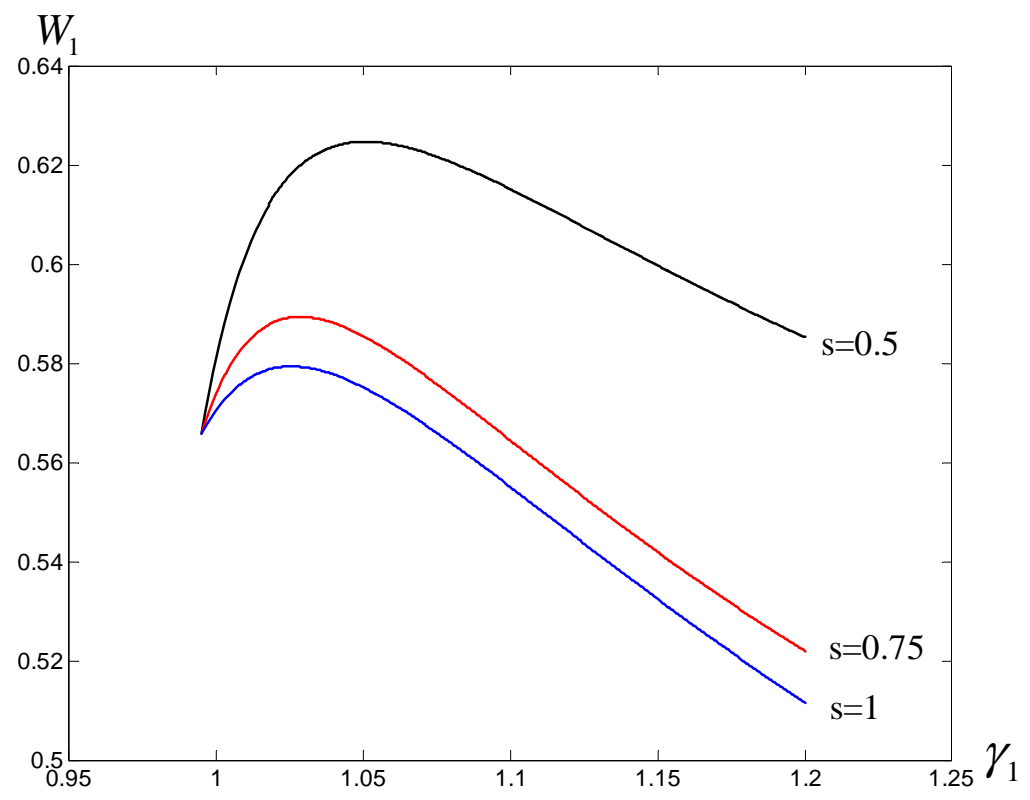

Figure 5. Country 1's welfare $W_{1}$ as a function of $\gamma_{1}$

In contrast to the benchmark case, an increase in $\gamma_{1}$ does not necessarily reduce $\theta$ when $s>1 / 2$. For example, when $s=0.75$ or 1 , an increase in $\gamma_{1}$ increases $\theta$ (not shown in Figure 5). As in the benchmark case, however, an increase in $\gamma_{1}$ reduces $n_{1}$ and generates a positive redistributive effect to the country. This is because the redistributive effect now has two terms (see (6.1)), the first of which is always positive when $s>1 / 2$.

To see more clearly how the incentive to inflate changes with $s$, we now examine the entire range $s \in[0.5,1]$. Figure 6.1 depicts how the overall welfare effect of inflation and its decomposition depend on $s$. In this figure, $\gamma_{2}$ is fixed at $\beta$ while $\gamma_{1}$ is increased marginally above $\beta$. Other parameters are given the same values as in Figure 5. As $s$ increases, the redistributive effect falls, the extensive effect first increases and then falls, and the overall welfare gain falls. The overall welfare gain is positive for all $s$, and this gain increases with the degree of market integration. 


\section{Welfare effects}

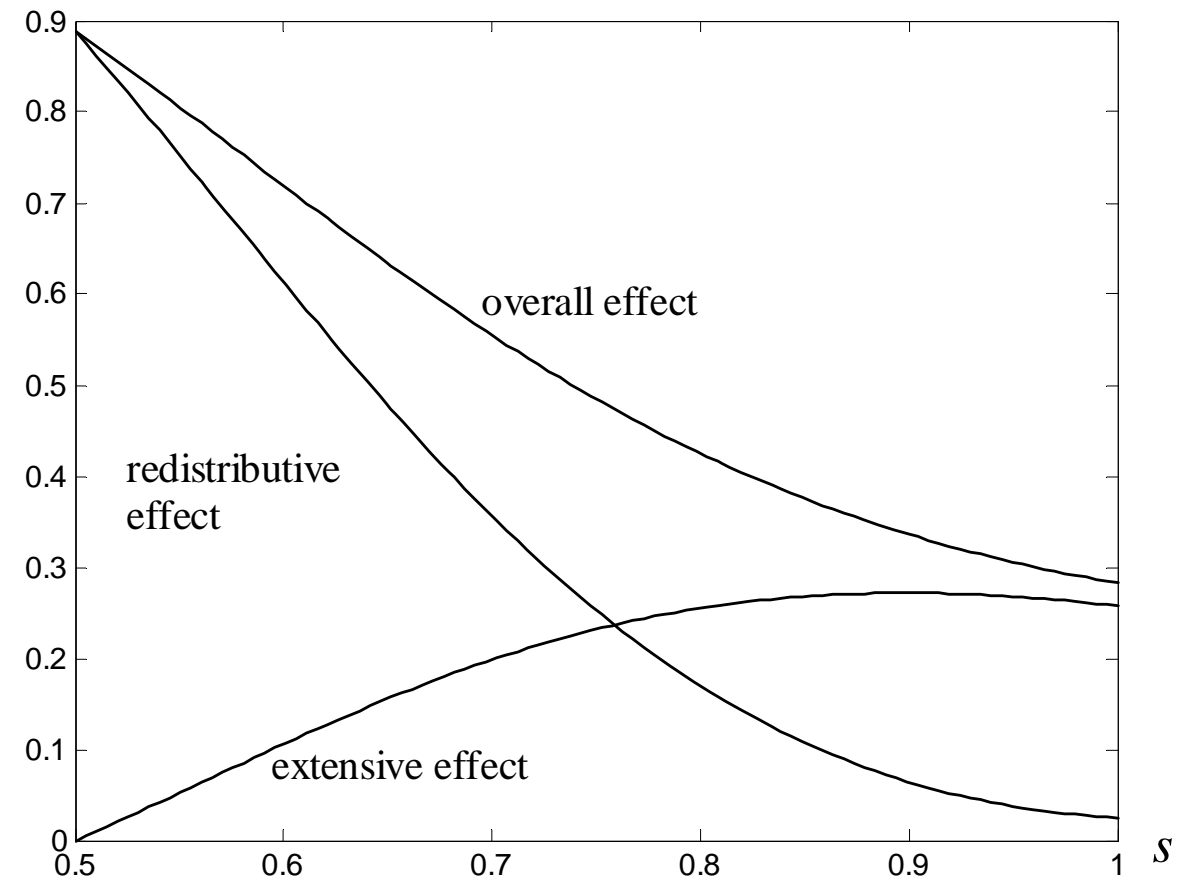

Figure 6.1. Effects of $\gamma_{1}$ on country 1's welfare and their composition

Figure 6.2 depicts how the common money growth rate of the two currencies in the Nash equilibrium changes with $s$. Not surprisingly, the equilibrium money growth rate is always above the Friedman rule. Also, the equilibrium money growth rate increases with market integration and reaches the maximum at $s=1 / 2$. Because inflation is not Pareto efficient in the economy, the results in Figure 6.2 suggest that integration of the two areas increases the need for monetary coordination between the two areas.

It is worthwhile mentioning that the incentive to inflate, and hence the need for coordination, exists even in the case $s=1$. When $s=1$, all goods are sold for the seller country's currency. This case resembles the cash-in-advance model described by Helpman (1981), with the modification that output is produced with elastically supplied labor. In this modification of Helpman's model, one can show that a unilateral increase in inflation reduces the country's consumption and welfare. ${ }^{17}$ There is no need for coordination, because neither country wants to inflate. In contrast, our model generates a gain from coordination even in the case $s=1$. This difference

\footnotetext{
${ }^{17}$ The proof is omitted here but is available upon request.
} 
arises from the non-Walrasian feature of the goods markets in our model. The non-Walrasian markets generate two dimensions which a country wants to explore with inflation. First, because the law of one price fails in general, a country can use inflation to alter the relative price between different types of matches to the country's advantage. Second, because the number of trades is important in addition to the quantity in each trade, inflation can generate a benefit in the extensive margin. These dimensions disappear when the goods markets are Walrasian.

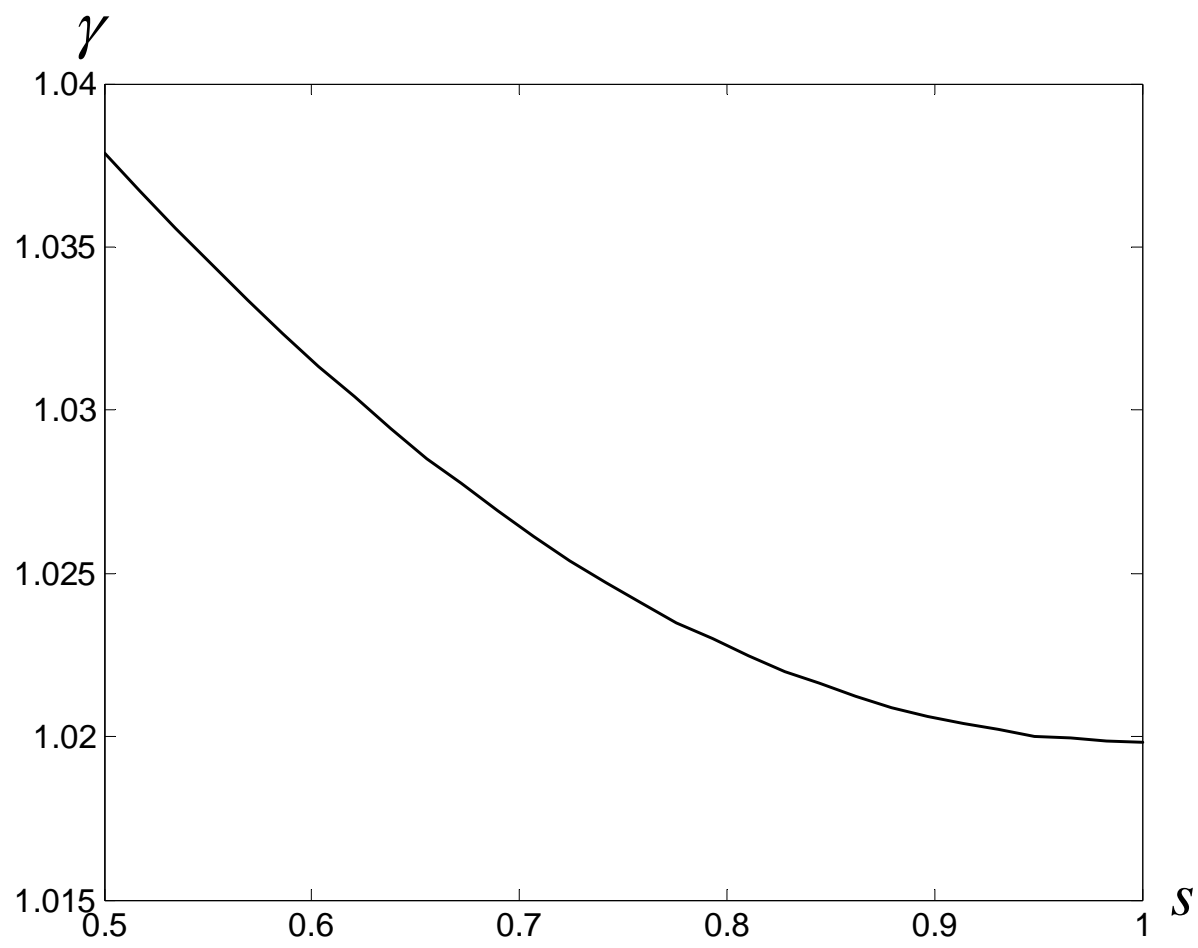

Figure 6.2. Nash equilibrium money growth at different $s$

\section{Taxing Foreign Holdings of Money}

It is well known that inflation can generate the classic effect of "beggar-thy-neighbour". For example, this effect can arise in models by Kareken and Wallace (1981), King et al. (1992) and Cooley and Quadrini (2003). In these models, however, inflation in a currency acts effectively as a tax on foreign holdings of the currency. If a country can directly tax foreign holdings of its currency, then the Friedman rule will be optimal. Because inflation in our model redistributes the purchasing power, an important question is whether a direct tax can replace the role of inflation. 
The answer is no. To show this, we introduce the direct tax below. ${ }^{18}$

Consider a buyer of country $i$ in a trade in area $j$. When the buyer buys from a domestic seller, let the total amount of money spent by the buyer be $x_{i j} /\left(1-\tau_{i j}\right)$. That is, the buyers pays the amount, $x_{i j}$, to the seller and the amount, $\tau_{i j} x_{i j} /\left(1-\tau_{i j}\right)$, as taxes. Similarly, when this buyer buys from a foreign seller, let the total amount spent by the buyer be $x_{i j}^{f} /\left(1-\tau_{i j}^{f}\right)$, of which the amount of taxes is $\tau_{i j}^{f} x_{i j}^{f} /\left(1-\tau_{i j}^{f}\right)$. Without loss of generality, we assume that the receipts of the taxes are burned. In the presence of the taxes, a country adjusts monetary transfers to maintain the growth rate of its currency at a constant. To save space, we omit the characterization of the equilibrium and examine only the case of a fully integrated economy, i.e., the case $s=1 / 2$.

We consider the following configuration of the taxes. A country taxes only foreign buyers and only when such buyers use the country's currency. That is, country 1 chooses $\tau_{21}^{f}=\tau_{21} \equiv \tau_{1}$ and country 2 chooses $\tau_{12}^{f}=\tau_{12} \equiv \tau_{2}$. Taxes on other transactions are zero. We compute the optimal choices numerically. Let us take the parameter values in section 6 . Fixing $\gamma_{2}=\beta$, we depict country 1's optimal choices of $\tau_{1}$ and $\gamma_{1}$ as functions of $\tau_{2}$ in Figures 7.1 and 7.2.

Two aspects of Figure 7.1 conform with the traditional argument presented at the beginning of this section. First, a country has incentive to tax foreign holdings of its currency. For example, the optimal choice of $\tau_{1}$ is positive for all $\tau_{2} \geq 0$. Second, the introduction of the tax reduces the incentive to inflate. Thus, part of the role of inflation in previous sections is to tax foreign holdings of a currency.

The tax is not a perfect substitute for inflation. As Figure 7.2 shows, setting the tax optimally does not eliminate a country's incentive to inflate. Rather, for all given values of $\tau_{2}$, a country's optimal inflation rate is above the Friedman rule. In the Nash equilibrium, $\tau_{1}=\tau_{2} \in(0, \infty)$ and $\gamma_{1}=\gamma_{2}>\beta$ (not shown in the figures). That is, each country will use both the tax and inflation to redistribute the purchasing power from the other country to itself. Monetary coordination between the two countries can still improve welfare of both countries.

Optimal inflation remains positive in the presence of the optimal tax because of the new dimensions discussed at the end of last section. First, even with the tax, a country can still benefit from the extensive effect of inflation. Second, inflation redistributes the purchasing power in more ways than the tax does, as a result of the deviations from the law of one price. Although the tax redistributes the purchasing power from foreign buyers to domestic buyers who trade in

\footnotetext{
${ }^{18}$ We thank Narayana Kocherlakota for suggesting this exercise.
} 
the same currency area, it does not increase the relative quantity of goods that the country's buyers obtain from a foreign seller versus a domestic seller when such buyers use the country's own currency in both trades. Because inflation achieves both types of redistribution, a country will set inflation above the Friedman rule in addition to using the tax.

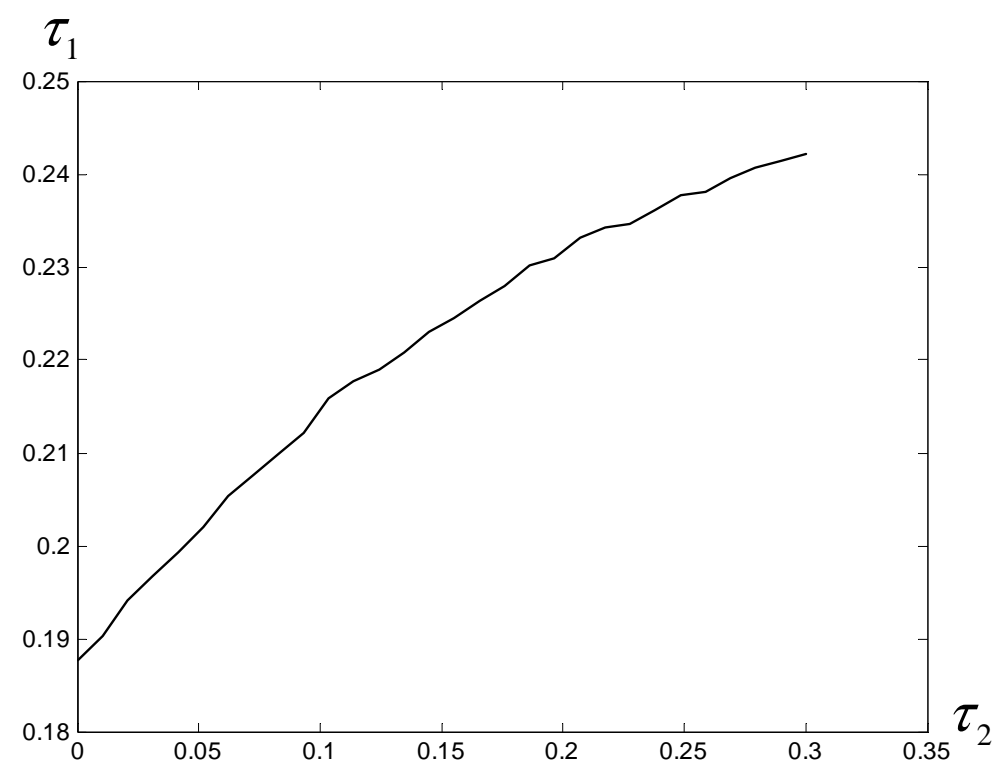

Figure 7.1. Optimal tax $\tau_{1}$ as a function of $\tau_{2}$

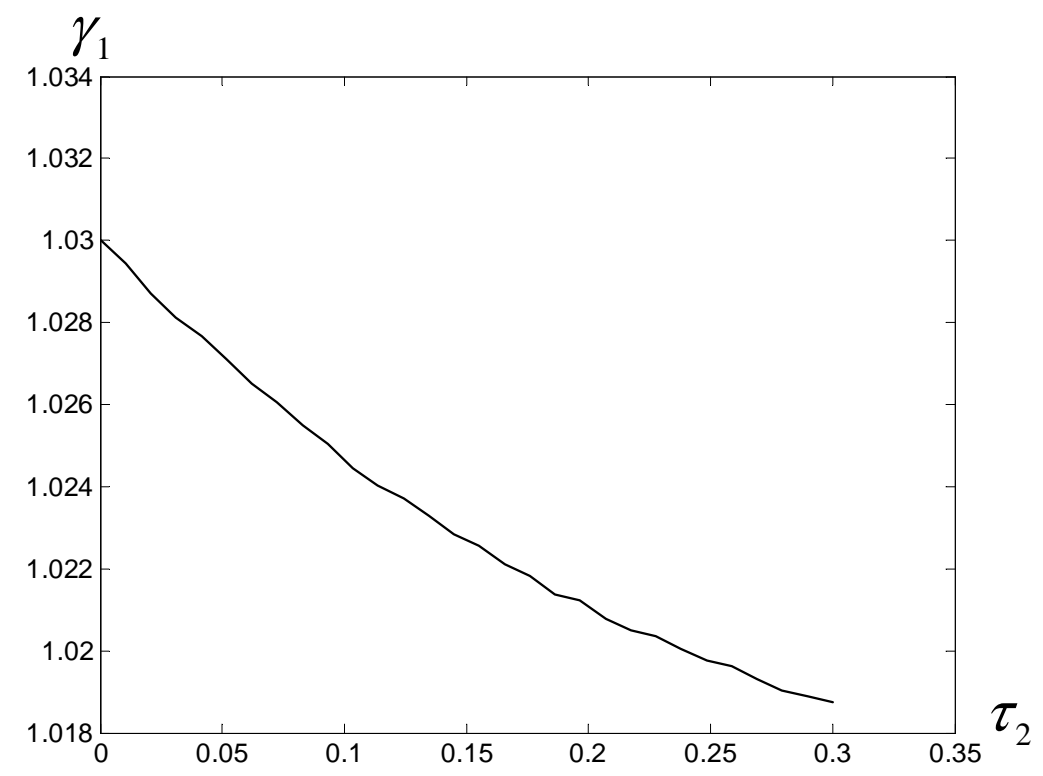

Figure 7.2. Optimal money growth $\gamma_{1}$ as a function of $\tau_{2}$

It is time to compare our model with Cooley and Quadrini (2003). As our model, Cooley and 32 
Quadrini examine the coordination on long-run inflation between two countries. In their model, production in each country uses inputs from both countries that are not perfectly substitutable. In addition, there is cash-in-advance constraint which requires that producers purchase inputs from a country with that country's currency. They show that each country has incentive to set inflation above the Friedman rule. However, because markets are Walrasian, there are no deviations from the law of one price or the extensive effect of inflation. Rather, inflation is a way to manipulate a country's terms of trade. As such, the incentive to inflate can be eliminated by allowing each country to directly tax foreign holdings of the country's currency. Moreover, the incentive to inflate will disappear when the cash-in-advance constraint is eliminated or when the two countries' inputs are perfect substitutes.

\section{Conclusion}

In this paper we integrate the recent development in monetary theory with international finance, in order to examine the coordination between two currency areas in setting long-run inflation. The model determines the value of each currency and the size of each currency area without imposing cash-in-advance constraints. We show that the two countries inflate above the Friedman rule in a non-cooperative game. Coordination between the two areas reduces inflation to the Friedman rule, increases consumption, and improves welfare of both countries. This gain from coordination increases as the two areas become more integrated in trade.

A country naturally has incentive to use inflation effectively as a tax on holdings of its currency by foreigners. However, this motive is not the main story of the current paper. A country will inflate even after it has set an optimal tax on foreign holdings of its currency. There are two new dimensions which a country tries to explore with inflation. Both arise from the non-Walrasian nature of the goods markets. First, inflation can affect the extensive margin of trade, which matters for households' expected utility. Second, there is a wedge between the two countries' valuations of a currency, which generates failures of the law of one price. A country can use inflation to affect this wedge for its own benefit, at the expense of the other country.

To see how inflation affects the deviations from the law of one price, suppose that country 1 sets its money growth at a higher rate than country 2. Because monetary transfers are given only to domestic households, country 1's residents hold more of both currencies in the steady state and, hence, value both currencies less than country 2's residents. That is, a seller of country 2 is 
willing to sell more goods for a currency than a seller of country 1. Exploring this difference in the valuation, a household of country 1 sends more buyers to buy from country 2 households than from other households in country 1 . As a result, consumption of country 1's households increases at the expense of country 2's households. This redistributive gain from unilateral inflation would disappear if the exchange for goods were centralized (and frictionless), in which case the law of one price would hold.

The outcome under policy competition is Pareto inefficient because inflation reduces the overall purchasing power of currencies and reduces total consumption (output). By coordinating the policy, the two countries can follow the Friedman rule which increases consumption and welfare of both countries. The need for coordination increases as the two currency areas become more integrated. We model the degree of integration as the fraction of sellers whom a country's household can send to the foreign currency area. With higher integration, a country's sellers can avoid a large part of the consequences of the country's inflation by selling to foreign buyers, while the country's buyers can still obtain the redistributive gain. As a result, higher integration increases the incentive to inflate and hence increases the need for monetary coordination.

Although monetary coordination improves welfare, it is not a Nash equilibrium in a one-shot game. Thus, the coordination outcome would not be sustainable if there were no punishment on deviations. One way to commit to the efficient outcome of coordination is for the two currency areas to adopt a common currency. Our results suggest that the need for such currency unification increases when the two areas are more integrated with each other in trade.

In addition to the above policy issues, our paper provides a tractable framework that generates values for the currencies from detailed descriptions of preferences and technologies, without resorting to cash-in-advance constraints. We hope that the framework will be useful in the future for examining a wide range of issues on currencies and exchange rates. For example, the framework generates deviations from the law of one price naturally. It may be worthwhile comparing these deviations with observations. 


\section{Appendix}

\section{A. Proof of Lemma 3.1}

First, we derive (3.15) from (3.3). Substituting (3.10) into (3.3), we have:

$$
\frac{q_{12}}{q_{11}}=G\left(n_{1}, \theta\right), \quad \frac{q_{21}}{q_{22}}=G\left(n_{2}, \frac{1}{\theta}\right),
$$

where the function $G$ is defined by (3.17). Substituting $\left(q_{11}, q_{12}\right)$ and $\left(q_{21}, q_{22}\right)$ from (3.11) and (3.12), the first equation above yields (3.15) and the second equation yields:

$$
\frac{1-s+s \theta^{1 / \sigma}}{s+(1-s) \theta^{1 / \sigma}}=\left[\frac{\mu\left(n_{2}\right)}{\mu\left(1-n_{2}\right)}\right]^{1-\frac{1}{\sigma}}\left[\frac{\left(\frac{\gamma_{1}}{\beta}-1\right) / \mu\left(1-n_{2}\right)+1}{\left(\frac{\gamma_{2}}{\beta}-1\right) / \mu\left(n_{2}\right)+1}\right]^{\frac{1}{\sigma}} .
$$

Second, we show $n_{2}=1-n_{1}$. Denote the right-hand side of (3.15) temporarily as $R H S\left(n_{1}\right)$. Then, the right-hand side of (A.1) is equal to $\operatorname{RHS}\left(1-n_{2}\right)$. Since the left-hand sides of (3.15) and (A.1) are identical, then $R H S\left(1-n_{2}\right)=R H S\left(n_{1}\right)$. To show $1-n_{2}=n_{1}$, it suffices to show that $R H S(n)$ is increasing in $n$. Because $\mu(n)$ is a decreasing function, and because $\gamma_{1}, \gamma_{2}>\beta$, the function $R H S(n)$ is indeed increasing in $n$.

Third, we derive (3.16). To do so, first use (2.4) - (2.7) to express the $\omega$ 'es as functions of $(q, f)$. Using these expressions and the fact that $n_{2}=1-n_{1}$, we obtain:

$$
\begin{aligned}
& \theta=\frac{\omega_{11}}{\omega_{21}}=\left(\frac{q_{11}}{q_{21}}\right)^{\sigma} \frac{m_{21}+f_{21}}{m_{11}-f_{11}}, \\
& \theta=\frac{\omega_{12}}{\omega_{22}}=\left(\frac{q_{12}}{q_{22}}\right)^{\sigma} \frac{m_{22}-e f_{21}}{m_{12}+e f_{11}} .
\end{aligned}
$$

From these equations we solve for $\left(f_{11}, f_{21}\right)$ as functions of $(\theta, q, m)$. Using these solutions, we can rewrite the equilibrium condition in the currency market, $f_{21}=f_{11}$, as follows:

$$
e\left\{m_{11}-\left[1+\theta\left(\frac{q_{21}}{q_{11}}\right)^{\sigma}\right]^{-1}\right\}=\left[1+\theta\left(\frac{q_{22}}{q_{12}}\right)^{\sigma}\right]^{-1}-m_{12} .
$$

We also substitute the above solution forms of $(\omega, f)$ into (3.8) to obtain an expression for $e$. The laws of motion of money holdings, (2.8) and (2.9), yield $\left(m_{11}, m_{12}\right)$. The ratios between the $q$ 's can be derived from (3.11) and (3.12). Substituting these results into (A.2), we obtain (3.16).

Finally, if $\gamma_{1}=\gamma_{2}=\gamma$, it is easy to verify that (3.15) and (3.16) are satisfied by $\left(n_{1}, \theta\right)=$ $(1 / 2,1)$. Then, (3.10), (3.11) and (3.12) imply $q_{i j}=q_{i j}^{f}=Q(\gamma)$ for all $i, j=1,2$, where $Q(\gamma)$ is defined by (3.13). QED 


\section{B. Proofs for Section 4}

We first prove Proposition 4.1. To establish existence and uniqueness of the equilibrium, we need to show that there is a unique solution for $n_{1}$ to (4.1). Once this is done, the $q$ 's are given by (3.10), (3.11), (3.12) and (3.14); $\theta$ is given by (3.16); and $e$ is given by (3.18). Moreover, from the laws of motion of the household's money holdings, we can solve the holdings of money by country 1 as follows:

$$
\begin{aligned}
& m_{11}=\frac{1}{\gamma_{1}}\left[\gamma_{1}-1+s \mu\left(n_{1}\right)+\frac{1-\mu\left(n_{1}\right)}{1+\theta^{\frac{\sigma}{\sigma-1}}}\right], \\
& m_{12}=\frac{1}{\gamma_{2}}\left[(1-s) \mu\left(1-n_{1}\right)+\frac{1-\mu\left(1-n_{1}\right)}{1+\theta^{\frac{\sigma}{\sigma-1}}}\right] .
\end{aligned}
$$

Here, $s=1 / 2$. The holdings by country 2 are $m_{2 k}=1-m_{1 k}$ for $k=1,2$. The amounts of

currency exchange are given by $f_{22}=e f_{11}$ and $f_{11}=m_{11}-\left(1+\theta^{\frac{\sigma}{\sigma-1}}\right)^{-1}$. These quantities and prices constitute a unique equilibrium.

To show that (4.1) has a unique solution, denote its left-hand side as $L H S\left(n_{1}\right)$ and the right-hand side as $R H S\left(n_{1}\right)$. Note that $L H S^{\prime}(n)<0$ and $R H S^{\prime}(n)>0$. To show that $n_{1}$ is uniquely determined in the equilibrium, it suffices to show that $L H S(0)>R H S(0)$ and $L H S(1)<R H S(1)$. These conditions are equivalent to the requirement that the parameter values lie in the set $\mathcal{D}$ specified in the proposition.

For given $n_{1}, R H S\left(n_{1}\right)$ is an increasing function of $\gamma_{1}$ and decreasing function of $\gamma_{2}$, while $\operatorname{LHS}\left(n_{1}\right)$ does not depend on $\left(\gamma_{1}, \gamma_{2}\right)$. Thus, it is easy to show the solution for $n_{1}$ to (4.1), denoted $N\left(\gamma_{1}, \gamma_{2}\right)$, has the properties $N_{1}\left(\gamma_{1}, \gamma_{2}\right)<0$ and $N_{2}\left(\gamma_{1}, \gamma_{2}\right)>0$. Moreover, if $\gamma_{1}=\gamma_{2}=\gamma$, then $n_{1}=1 / 2$ solves (4.1). This completes the proof of Proposition 4.1.

To prove Lemma 4.2, define $e\left(\gamma_{1}, \gamma_{2}\right)$ by (4.2). Setting $s=1 / 2$ in (3.16), we have

$$
\theta^{\frac{\sigma}{\sigma-1}}=1+\frac{\gamma_{2}\left(1-n_{1}\right)\left[G\left(n_{1}, \theta\right)\right]^{\sigma}}{\left(\gamma_{1}-1\right) n_{1}+\frac{1}{2} L\left(n_{1}\right)+\frac{1}{2} L\left(1-n_{1}\right)\left[G\left(n_{1}, \theta\right)\right]^{\sigma}} \Delta\left(\gamma_{1}, \gamma_{2}\right)
$$

where

$$
\Delta\left(\gamma_{1}, \gamma_{2}\right)=1-\frac{1}{\gamma_{2}}-\left(1-\frac{1}{\gamma_{1}}\right) e\left(\gamma_{1}, \gamma_{2}\right) .
$$

Then, it is clear that $\theta>1$ if and only if $\Delta>0$.

To examine $\Delta$, we examine $e$ first. Use (4.1) to substitute for $\mu\left(n_{1}\right) / \mu\left(1-n_{1}\right)$, we rewrite (4.2) as:

$$
e\left(\gamma_{1}, \gamma_{2}\right)=\frac{n}{1-n} \frac{\frac{1}{\beta}-[1-\mu(1-n)] \frac{1}{\gamma_{2}}}{\frac{1}{\beta}-[1-\mu(n)] \frac{1}{\gamma_{1}}}
$$


where $n=N\left(\gamma_{1}, \gamma_{2}\right)$ is the solution to (4.1) for $n_{1}$. Since $\mu(n)<1$ for all $n$, the right-hand side of the above expression for $e$ is an increasing function of $n$ and $\gamma_{2}$, and a decreasing function of $\gamma_{1}$. Since $n=N\left(\gamma_{1}, \gamma_{2}\right)$ decreases in $\gamma_{1}$ and increases in $\gamma_{2}$, then $e\left(\gamma_{1}, \gamma_{2}\right)$ decreases in $\gamma_{1}$ and increases in $\gamma_{2}$. Because $e(\gamma, \gamma)=1$ for all $\gamma>\beta$, then $e>1$ if and only if $\gamma_{1}<\gamma_{2}$.

Now, return to $\Delta\left(\gamma_{1}, \gamma_{2}\right)$. Clearly, $\Delta(\gamma, \gamma)=0$ for all $\gamma>\beta$. Suppose $\gamma_{1}<\gamma_{2}$. Then, $e\left(\gamma_{1}, \gamma_{2}\right)>1$. We derive the conditions (in the lemma) for $\Delta>0$, and hence for $\theta>1$. If $\gamma_{2} \leq 1$, then for all $\beta<\gamma_{1}<\gamma_{2}$, we have:

$$
\Delta>\left(1-\frac{1}{\gamma_{2}}\right)\left[1-e\left(\gamma_{1}, \gamma_{2}\right)\right] \geq 0
$$

The first inequality comes from $\gamma_{1}<\gamma_{2}$ and the second inequality comes from $\gamma_{2} \leq 1$ and $e\left(\gamma_{1}, \gamma_{2}\right)>1$. If $\gamma_{2}>1$, then for all $\beta<\gamma_{1} \leq 1$, we have:

$$
\Delta>\left(1-\frac{1}{\gamma_{1}}\right)\left[1-e\left(\gamma_{1}, \gamma_{2}\right)\right] \geq 0 .
$$

For $\gamma_{2}>1$, let $\gamma_{0}$ be the minimum value of $\gamma(>\beta)$ that satisfies $\Delta\left(\gamma, \gamma_{2}\right)=0$. Because $\Delta\left(\gamma_{2}, \gamma_{2}\right)=0$, then $\gamma_{0}$ exists and $\gamma_{0} \leq \gamma_{2}$. Also, $\gamma_{0}>1$, because $\Delta\left(1, \gamma_{2}\right)>0$ for $\gamma_{2}>1$. Thus, if $\gamma_{2}>1$, then $\Delta>0$ for all $\gamma_{1}<\gamma_{0}$. This completes the proof of Lemma 4.2. QED

\section{Proofs for Section 5}

We prove Proposition 5.1. First, we show that $d W_{1} / d \gamma_{1}>0$ at $\gamma_{1}=\beta$, given $\gamma_{2}=\beta$. In the process, we also show $d n_{1} / d \gamma_{1}<0$ and $d \theta / d \gamma_{1}<0$. Rewrite country 1's welfare level as:

$$
\begin{aligned}
W_{1}= & T_{11}^{1}\left[A q_{11}-\left(q_{11}\right)^{\sigma}\right]+T_{11}^{2}\left[A q_{12}-\left(q_{12}\right)^{\sigma}\right] \\
& +\left[T_{12}^{1} A q_{11}^{f}-T_{21}^{1}\left(q_{21}^{f}\right)^{\sigma}\right]+\left[T_{12}^{2} A q_{12}^{f}-T_{21}^{2}\left(q_{22}^{f}\right)^{\sigma}\right] .
\end{aligned}
$$

The first two terms are net surpluses that the household's agents obtain in trades with domestic agents and the last two terms are net surpluses in trades with foreign agents. Differentiate the above welfare level with respect to $\gamma_{1}$ and evaluate the derivative at $\gamma_{1}=\gamma_{2}=\beta$. Utilizing (3.10), (3.11), (3.12), (3.14) and the result $n_{2}=1-n_{1}$, we get:

$$
\left.q^{-\sigma} \frac{d W_{1}}{d \gamma_{1}}\right|_{\gamma_{1}=\gamma_{2}=\beta}=-\mu\left(\frac{1}{2}\right)\left[\frac{1}{2(\sigma-1)}+1\right] \frac{d \theta}{d \gamma_{1}}
$$

Here $\gamma_{2}$ is taken as given in the derivatives of $n_{1}$ and $\theta$, and both derivatives are evaluated at $\gamma_{1}=\gamma_{2}=\beta$. Differentiating (4.1) with respect to $\gamma_{1}$ and evaluating the derivative at $\gamma_{1}=\gamma_{2}=\beta$, we get:

$$
\frac{d n_{1}}{d \gamma_{1}}=-\left[\beta(1-\psi)(\sigma-1) \mu\left(\frac{1}{2}\right)\right]^{-1}<0 .
$$


Using this result and differentiating (3.16), we have:

$$
\frac{d \theta}{d \gamma_{1}}=-\left(1-\frac{1}{\sigma}\right) \frac{(1-\beta)[1+2 \sigma(1-\psi)]+2 \beta(1-\psi)(\sigma-1) \mu\left(\frac{1}{2}\right)}{\beta \mu\left(\frac{1}{2}\right)(1-\psi)(\sigma-1)\left[\beta-1+\mu\left(\frac{1}{2}\right)\right]}<0 .
$$

Then, (C.1) implies $\left.\frac{d W_{1}}{d \gamma_{1}}\right|_{\gamma_{1}=\gamma_{2}=\beta}>0$. This completes the proof of Proposition 5.1.

Now we prove Proposition 5.2. A Nash equilibrium is a pair, $\left(\gamma_{1}, \gamma_{2}\right)$, which solves the following equations that characterize the two countries' best responses to each other:

$$
\frac{d W_{1}}{d \gamma_{1}}=0, \frac{d W_{2}}{d \gamma_{2}}=0
$$

We restrict our search for the solutions to the ones that have $\gamma_{1}=\gamma_{2}$. Calculating the derivative $d W_{1} / d \gamma_{1}$ and evaluating it at $\gamma_{1}=\gamma_{2}=\gamma$, we have:

$$
\left.\frac{1}{T_{11}^{1}} \frac{d W_{1}}{d \gamma_{1}}\right|_{\gamma_{1}=\gamma_{2}=\gamma}=F(\gamma)
$$

where

$$
\begin{aligned}
& F(\gamma)=-2\left[q^{\sigma}+\frac{1}{\sigma-1} A q\right] \theta^{\prime}-\frac{2\left(A-\sigma q^{\sigma-1}\right)}{\beta \mu\left(\frac{1}{2}\right)(\sigma-1)} q^{\sigma}, \\
& \theta^{\prime}=-\left(\frac{\sigma-1}{\sigma}\right) \frac{4(\gamma-1)[\sigma(1-\psi)+1] n^{\prime}+1}{\gamma-1+\mu\left(\frac{1}{2}\right)}, \\
& n^{\prime}=-\left\{4(1-\psi)\left[\beta(\sigma-1) \mu\left(\frac{1}{2}\right)+(\gamma-\beta) \sigma\right]\right\}^{-1} .
\end{aligned}
$$

Thus, $\left.\frac{d W_{1}}{d \gamma_{1}}\right|_{\gamma_{1}=\gamma_{2}=\gamma}=0$ if and only if $F(\gamma)=0$. Similarly, $\left.\frac{d W_{2}}{d \gamma_{2}}\right|_{\gamma_{1}=\gamma_{2}=\gamma}=0$ if and only if $F(\gamma)=0$. Therefore, a solution to $F(\gamma)=0$ constitutes a Nash equilibrium.

The function $F(\gamma)$ is continuous for all $\gamma \geq \beta$, provided that $\beta>1-\mu\left(\frac{1}{2}\right)$. Proposition 5.1 shows that $F(\beta)>0$. Let $\gamma_{A}$ be such that $\theta^{\prime}=0$. Clearly, $F\left(\gamma_{A}\right)<0$. Also, because $n^{\prime}<0$, it is easy to verify that $\gamma_{A}>1>\beta$. Thus, there exists $\gamma^{*} \in\left(\beta, \gamma_{A}\right)$ such that $F\left(\gamma^{*}\right)=0$. This level $\gamma^{*}$ is the common rate of growth of the two currencies in a Nash equilibrium. QED 


\section{References}

[1] Camera, G., Craig, B. and C. Waller, 2004, "Currency competition in a Fundamental Model of Money," Journal of International Economics 64, 521-544.

[2] Cooley, T.F. and V. Quadrini, 2003, "Common currencies vs. monetary independence," Review of Economic Studies 70, 785-806.

[3] Craig, B. and C. Waller, 2004, "Dollarization and currency exchange," Journal of Monetary Economics 51,671-689.

[4] Head, A. and S. Shi, 2003, "A fundamental theory of exchange rates and direct currency trades," Journal of Monetary Economics 50, 1555-1591.

[5] Helpman, E., 1981, "An exploration in the theory of exchange rate regimes," Journal of Political Economy 89, 865-890.

[6] Kareken, J. and N. Wallace, 1981, "On the indeterminacy of equilibrium exchange rates," Quarterly Journal of Economics 96, 207-222.

[7] King, R.G., Wallace, N. and W.E. Weber, 1992, "Nonfundamental uncertainty and exchange rates," Journal of International Economics 32, 83-108.

[8] Kiyotaki, N. and R. Wright, 1993, "A search-theoretic approach to monetary economics," American Economic Review 83, 63-77.

[9] Matsuyama, M., Kiyotaki, N. and A. Matsui, 1993, "Towards a theory of international currency," Review of Economic Studies 60, 283-307.

[10] Obstfeld, M., 1998, "Open-economy macroeconomics: developments in theory and policy," Scandinavian Journal of Economics 100, 247-275.

[11] Obstfeld, M. and K. Rogoff, 2002, "Global implications of self-oriented national monetary rules," Quarterly Journal of Economics 117, 503-535.

[12] Rogoff, K., 1985, "Can international monetary policy cooperation be counterproductive?" Journal of International Economics 18, 199-217. 
[13] Shi, S., 1995, "Money and prices: a model of search and bargaining," Journal of Economic Theory 67, 467-496.

[14] Shi, S., 1997, "A divisible search model of fiat money," Econometrica 65, 75-102.

[15] Trejos, A. and R. Wright, 1995, "Search, bargaining, money, and prices," Journal of Political Economy 103, 118-141.

[16] Wright, R. and A. Trejos, 2001, "International currency," Advances in Macroeconomics 1 (no. 1), article 3 .

[17] Zhou, R., 1997, "Currency exchange in a random search model," Review of Economic Studies 64, 289-310. 